\title{
Bilayered chitosan-based scaffolds for osteochondral tissue engineering: Influence of hydroxyapatite on in vitro cytotoxicity and dynamic bioactivity studies in a specific double-chamber bioreactor
}

\author{
Patrícia B. Malafaya ${ }^{\mathrm{a}, \mathrm{b}, *}$, Rui L. Reis ${ }^{\mathrm{a}, \mathrm{b}}$ \\ a 3B's Research Group, Biomaterials, Biodegradables and Biomimetics, Department of Polymer Engineering, University of Minho, \\ Headquarters of the European Institute of Excellence on Tissue Engineering and Regenerative Medicine, AvePark, Zona Industrial da Gandra, \\ S. Cláudio do Barco, 4806-909 Caldas das Taipas, Guimarães, Portugal \\ ${ }^{\mathrm{b}}$ IBB - Institute for Biotechnology and Bioengineering, PT Government Associated Laboratory, Caldas das Taipas, Portugal
}

Received 27 March 2008; received in revised form 23 September 2008; accepted 23 September 2008

Available online 4 October 2008

\begin{abstract}
Osteochondral tissue engineering presents a current research challenge due to the necessity of combining both bone and cartilage tissue engineering principles. In the present study, bilayered chitosan-based scaffolds are developed based on the optimization of both polymeric and composite scaffolds. A particle aggregation methodology is proposed in order to achieve an improved integrative bone-cartilage interface needed for this application, since any discontinuity is likely to cause long-term device failure. Cytotoxicity was evaluated by the MTS assay with the L929 fibroblast cell line for different conditions. Surprisingly, in composite scaffolds using unsintered hydroxyapatite, cytotoxicity was observed in vitro. This work reports the investigation that was conducted to overcome and explain this behaviour. It is suggest that the uptake of divalent cations may induce the cytotoxic behaviour. Sintered hydroxyapatite was consequently used and showed no cytotoxicity when compared to the controls. Microcomputed tomography (micro-CT) was carried out to accurately quantify porosity, interconnectivity, ceramic content, particle and pore sizes. The results showed that the developed scaffolds are highly interconnected and present the ideal pore size range to be morphometrically suitable for the proposed applications. Dynamical mechanical analysis (DMA) demonstrated that the scaffolds are mechanically stable in the wet state even under dynamic compression. The obtained elastic modulus was, respectively, $4.21 \pm 1.04,7.98 \pm 1.77$ and $6.26 \pm 1.04 \mathrm{MPa}$ at $1 \mathrm{~Hz}$ frequency for polymeric, composite and bilayered scaffolds. Bioactivity studies using both a simulated body fluid (SBF) and a simulated synovial fluid (SSF) were conducted in order to assure that the polymeric component for chondrogenic part would not mineralize, as confirmed by scanning electron microscopy (SEM), inductively coupled plasma-optical emission spectroscopy (ICP) and energy-dispersive spectroscopy (EDS) for different immersion periods. The assays were carried out also under dynamic conditions using, for this purpose, a specifically designed double-chamber bioreactor, aiming at a future osteochondral application. It was concluded that chitosan-based bilayered scaffolds produced by particle aggregation overcome any risk of delamination of both polymeric and composite parts designed, respectively, for chondrogenic and osteogenic components that are mechanically stable. Moreover, the proposed bilayered scaffolds could serve as alternative, biocompatible and safe biodegradable scaffolds for osteochondral tissue engineering applications.
\end{abstract}

(C) 2008 Acta Materialia Inc. Published by Elsevier Ltd. All rights reserved.

Keywords: Osteochondral; Tissue engineering; Scaffolds; Particle aggregation; Chitosan

\footnotetext{
${ }^{*}$ Corresponding author. Address: 3B's Research Group, Biomaterials, Biodegradables and Biomimetics, Department of Polymer Engineering, University of Minho, Headquarters of the European Institute of Excellence on Tissue Engineering and Regenerative Medicine, AvePark, Zona Industrial da Gandra, S. Cláudio do Barco, 4806-909 Caldas das Taipas, Guimarães, Portugal. Tel.: +35 1253510908 .

E-mail address: pmalafaya@dep.uminho.pt (P.B. Malafaya).
}

\section{Introduction}

Osteochondral defects are lesions of the articular cartilage where the underlying bone tissue is also damaged. Currently, osteochondral defects are mostly treated by (i) osteochondral autograft transfer, taken from an outer 
region of the joint [1]; (ii) filling the lesion with autologous, precultured chondrocytes (autologous chondrocyte transplantation, ACT) [2]; or (iii) matrix-induced autologous chondrocyte implantation [3]. Although some studies have achieved success in repairing small cartilage defects, no accepted method for complete repair of osteochondral defects exists [4]. Large osteochondral defects are associated with mechanical instability and are accepted indications for surgical intervention to prevent development of degenerative joint disease. Ideally, a large osteochondral defect should be repaired with a graft that can provide mechanical stability and allow early postoperative function under physiological loading conditions [5]. In addition, the graft should integrate with the host tissue both structurally and functionally, since any discontinuity can incite longterm device failure [6].

The requirements for an osteochondral graft could potentially be met by using a tissue-engineered osteochondral (bone-cartilage) composite of predefined size and shape, generated in vitro using autologous cells. Such a graft would provide mechanical stability from the time of implantation, minimize donor site morbidity by using cell expansion techniques, and eliminate complications related to the use of allografts and/or mechanical devices. The bone region of the engineered osteochondral composite may further help anchor the graft within the defect, since a bone-to-bone interface integrates better and faster than a cartilage-to-cartilage interface [6].

The overall objective of tissue engineering is the restoration of normal tissue function. Ideally, lost or damaged tissue should be replaced by an engineered graft that can reestablish the appropriate structure, composition, cell signalling and function(s) of the native tissue [7]. The clinical utility of tissue engineering likely depends on our ability to replicate the site-specific properties of the tissue being replaced across different size scales and provide the continuity and strength of the interface with the neighbouring host tissues [8]. Therefore, for an osteochondral defect, one should consider the need for simultaneous regeneration of both cartilage and subchondral bone, making osteochondral tissue engineering a challenge to present-day research since it necessitates the combining of both bone and cartilage tissue engineering principles.

Several possible strategies for developing hybrid constructs for osteochondral tissue engineering have been published [5,9-11], namely: (i) cell culturing is performed independently on two sides, which are integrated before implantation; (ii) two different cell sources are seeded in the two sides of a single- or double-phase scaffold, and cultivated in a special bioreactor with two separated chambers; and ideally (iii) common progenitor cells are seeded in the two sides of a biphasic scaffold that contains different differentiation agents and then cultivated in a bioreactor with one or two chambers. For these, several bioreactors have been described, as reviewed $[8,12]$ and proposed [13] by different authors. Bioreactor systems can provide the technological means to reveal fundamental mechanisms of cell function in a three-dimensional (3-D) environment and the potential to improve the quality of engineered tissues, providing environmental control, biochemical and mechanical cues. Several bioreactor systems, such as rotating bioreactors and perfused cartridges or chambers, have been used. Nevertheless, we believe that double-chamber bioreactors [12,13] consisting of one chamber for the culture of the chondrogenic part and another chamber for the osteogenic part, seems to be the most suitable for osteochondral applications. The double-chamber bioreactor should allow for the culture of chondrocytes, osteoblasts or common progenitor cells in two different cell culture media.

Many tissue engineering scaffolding strategies dealing with osteochondral repair engage the design of bilayered scaffolds that could regenerate both cartilage and subchondral bone involving different combinations of materials, morphologies and properties in both parts of the scaffold. Nevertheless, some researchers suggest that osteochondral defects could be regenerated from single-layer scaffolds by seeding autologous chondrocytes at the top of the 3-D scaffold to create a cell-scaffold construct for in vivo implantation $[14,15]$ or that complex tissue grafts could be engineering with gradients of molecular, structural and functional properties. Several strategies with single-layer materials can be followed, as recently reviewed by Mano and Reis [9]. Nevertheless, it is more widely accepted that a bilayered structure would be more challenging to produce but more suitable for regenerating an osteochondral defect able to incorporate/induce different types of cells in a favourable environment requiring different chemical surroundings and mechanical requirements, leading to the growth of two different tissues, with different biological requirements.

Bearing this in mind, different approaches have been reported. Swieszkowski et al. [4] proposed two different systems using bone marrow-derived mesenchymal cells cultured in chondrogenically and osteogenically favourable conditions. The biphasic scaffolds consist of fibrin and polycaprolactone (PCL) and PCL and PCL/ $\beta$-tricalcium phosphate (TCP), where the PCL-based scaffolds are fabricated via fused deposition modelling (rapid prototyping system). Both phases are fabricated and seeded separately, then integrated into a single construct by using fibrin glue. Their results demonstrate the potential of the porous PCL and PCL-TCP scaffolds in promoting bone healing. Scotti et al. [16] reported a biphasic composite made of an expanded chondrocytes-fibrin glue gel composite with a calcium phosphate scaffold. This paper focused mainly on the problem of the neocartilage-to-bone integration, so no cells were used in the osteogenic part of the biphasic scaffold. Hence, the bilayered construct showed a triphasic structure, with a cartilaginous zone, an intermediate zone with the chondrocytes-fibrin glue complex penetrating the calcium phosphate and a zone free from cells, made of the remaining part of the calcium phosphate scaffold [16]. 
In the present study, particle aggregation methodology is proposed to fabricate bilayered scaffolds for osteochondral tissue engineering in order to achieve an improved integrative bone and cartilage interface needed for this application. Chitosan was chosen due to its structural similarity to the glycosaminoglycans (GAGs) found in extracellular matrices, such as native articular cartilage, which play a key role in modulating the morphology, differentiation and function of chondrocytes $[17,18]$. For the osteogenic part, composites with hydroxyapatite (HA) were developed to mimic the bony structure. Glutaraldehyde was used as a crosslinking agent to further improve the mechanical performance. An extensive characterization is reported, including in vitro cytotoxicity, morphometric analysis and dynamic-mechanical behaviour in the hydrated state. Furthermore, dynamic bioactivity assays were carried out in a specifically designed double-chamber bioreactor.

\section{Materials and methods}

\subsection{Scaffolds production}

The scaffolds were produced as described elsewhere [19]. Briefly, chitosan (medium molecular weight and $\sim 85 \%$ deacetylated) was ground and dissolved overnight in acetic acid (1 vol.\%) to obtain a chitosan solution (2 wt.\%). Unless otherwise stated, all chemicals were bought from Sigma-Aldrich and used as received. In composite particles production, $20 \mathrm{wt} . \%$ of unsintered HA (Camceram II, coating powder, CAM Implants BV, Leiden, The Netherlands) or sintered HA (Captal's ${ }^{\circledR}$ HA, Plasma Biotal Ltd., Tideswell, UK) was homogeneously dispersed in the chitosan solution. After complete dissolution and filtration, the prepared solutions were extruded through a syringe at constant rate $\left(10 \mathrm{ml} \mathrm{h}^{-1}\right)$ to form chitosan droplets into a $\mathrm{NaOH}(1 \mathrm{M})$ precipitation bath where particles with regular diameter were formed. The chitosan particles were left in the precipitation bath until precipitation was complete and then washed repeatedly with distilled water until a $\mathrm{pH}$ of 7 was achieved.

For composite and bilayered scaffolds production, the composite particles were submitted to a crosslinking reaction with glutaraldehyde. For scaffold production optimization, different glutaraldehyde concentrations $(0.01 \%$, $0.025 \%, 0.05 \%$ and $0.5 \%$ for $15 \mathrm{~min}$ ) were used. Scaffolds were further washed with glycine solution $(0.2$ and $1 \mathrm{M}$ for $15 \mathrm{~min}$ ) in order to block any free aldehyde groups. After each step, scaffolds were washed with distilled water. Unless otherwise stated, composite scaffolds were crosslinked with $0.01 \%$ glutaraldehyde and washed with $1 \mathrm{M}$ glycine, both for $15 \mathrm{~min}$, as described in Table 1 . The particles were then pressed into moulds and left to dry in an oven at $60{ }^{\circ} \mathrm{C}$ for 3 days. The scaffolds obtained were of a cylindrical shape, $8 \mathrm{~mm}$ in height and $5 \mathrm{~mm}$ in diameter.
Table 1

Summary of scaffold abbreviations and composition.

\begin{tabular}{lllll}
\hline Abbreviation & Scaffolds & \multicolumn{2}{l}{ Composition } \\
\cline { 3 - 5 } & & $\begin{array}{l}\text { Chitosan:HA } \\
\text { ratio }\end{array}$ & $\begin{array}{l}\text { Glutaraldehyde } \\
(\% \mathrm{vv})\end{array}$ & $\begin{array}{l}\text { Glycine } \\
{[\mathrm{M}]}\end{array}$ \\
\hline $\mathrm{C}$ & Polymeric & $100: 0$ & - & - \\
CHA & Composite & $80: 20$ & $0.01 \%, 15 \mathrm{~min}$ & $\begin{array}{l}1 \mathrm{M}, \\
15 \mathrm{~min}\end{array}$ \\
BiCCHA & Bilayered structures (polymeric + composite) & \\
\hline
\end{tabular}

\subsection{Evaluation of cell viability}

To assess the possible cytotoxicity of the developed scaffolds, the in vitro cell viability was assessed using MTS assay (3-(4,5-dimethylthiazol-2-yl)-5-(3-carboxylmethoxyphenyl)-2-(4-sulfophenyl)-2 $H$-tetrazolium) (Cell Titer $96^{\circledR}$ AQueous Solution Cell Proliferation Assay, G3580, Promega, USA) according to ISO/EN 10993 part 5 guidelines, which determines whether cells are metabolically active. This cytotoxicity test is based on the bioreduction of the substrate (MTS) into a brown formazan product by dehydrogenase enzymes in metabolically active cells, directly related with cell viability. For this purpose, materials $(n=3)$ were incubated in culture medium for $24 \mathrm{~h}$ at $37^{\circ} \mathrm{C}$ with constant shaking after sterilization by ethylene oxide (EtO) in conditions that have been described previously [20].

Latex was also incubated as a positive control for cell death. A rat lung fibroblast cell line (L929) acquired from the European Collection of Cell Cultures was used for the studies. The cells were grown as monolayers in Dulbecco's modified Eagle's medium (DMEM) supplemented with $10 \%$ foetal bovine serum (Biochrom, Berlin, Germany; Heat Inactivated) and a $1 \%$ antibiotic-antimycotic mixture. Cultured L929 cells were trypsinised using Trypsin-EDTA (Gibco, Invitrogen Corporation) and plated into 96-well micrometer plates $\left(200 \mu 1\right.$ well $\left.^{-1}\right)$ at $6.6 \times 10^{4}$ cells well ${ }^{-1}$. The plates were incubated for $24 \mathrm{~h}$ at $37^{\circ} \mathrm{C}$ in a humidified atmosphere of $5 \% \mathrm{CO}_{2}$ in air. The medium was then replaced by the previous prepared materials extracts after sterilized by filtration $(0.45 \mu \mathrm{m}$ pore size $)$ using culture medium by itself as a negative control. After $72 \mathrm{~h}$ of incubation, the cell culture was treated with MTS (in medium without phenol red) and incubated for a further $3 \mathrm{~h}$ at $37^{\circ} \mathrm{C}$ in a humidified atmosphere of $5 \% \mathrm{CO}_{2}$ in air. At this stage, culture medium with MTS was transferred to new wells. The optical density, which is directly proportional to the cellular activity (it reflects the mitochondrial activity), was read on a microplate reader (Synergy HT, BioTek Instruments) at $490 \mathrm{~nm}$.

\subsubsection{Inductively coupled plasma-optical emission spectroscopy}

Following the protocol for materials extracts performed in the MTS assay, the different sample extracts solutions were further analyzed in order to determine the concentra- 
tions of calcium, phosphorus, silicon, magnesium and sodium elements. The element concentrations were measured by inductively coupled plasma-optical emission spectroscopy (ICP-OES JY70 plus, Jobin Yvon, France). Triplicate samples were analyzed for each condition. For this purpose, materials were incubated in DMEM for $24 \mathrm{~h}$ at $37^{\circ} \mathrm{C}$ with constant shaking, after sterilization by EtO in conditions that have been described previously [20]. After that, the elemental concentrations of the prepared materials extracts sterilized by filtration $(0.45 \mu \mathrm{m}$ pore) were measured, using cell culture medium itself as the control.

\subsection{Microcomputed tomography}

The scaffolds $(n=3)$ were analysed using microcomputed tomography (micro-CT). Micro-CT was carried out with a high-resolution micro-CT Skyscan 1072 scanner (Skyscan, Kontich, Belgium) using a resolution of pixel size of $7.53 \mu \mathrm{m}$ and an integration time of $1.7 \mathrm{~ms}$. The X-ray source was set at $40 \mathrm{keV}$ of energy and $250 \mu \mathrm{A}$ of current. Approximately 400 projections were acquired over a rotation range of $180^{\circ}$, with a rotation step of $0.45^{\circ}$. Data sets were reconstructed using standardized conebeam reconstruction software (NRecon v1.4.3, SkyScan). The output format for each sample was 300 serial $1024 \times 1024$ bitmap images. Representative data sets of 200 slices were segmented into binary images with a dynamic threshold of 40-255 to access the porosity and $150-255$ to identify the ceramic phase (grey values). The same representative volume of interest was analysed for all the samples. These data sets were used for morphometric analysis (CT Analyser, v1.5.1.5, SkyScan) and to build 3-D models (ANT 3-D creator, v2.4, SkyScan). The morphometric analysis included histograms of the scaffolds, porosity and interconnectivity, mean pore and particle size, pore size and ceramic phase distribution. Three-dimensional virtual models of representative regions in the bulk of the scaffolds were created, visualized and registered using both image processing softwares (CT Analyser and ANT 3-D creator).

\subsection{Dynamical mechanical analysis}

Dynamic mechanical analysis (DMA) was conducted in order to characterize the mechanical behaviour of chitosan particle-aggregated scaffolds in wet state, under dynamic compression solicitation. Cylindrical chitosan-based scaffolds were immersed in phosphate-buffered solution (PBS) at physiological $\mathrm{pH}$ and temperature $(\mathrm{pH} 7.4$ and $37^{\circ} \mathrm{C}$ ) for 3 days for complete hydration. The scaffolds were then were subjected to compression cycles of increasing frequencies ranging from 0.1 to $40 \mathrm{~Hz}$ with constant dynamic displacements of $0.03 \mathrm{~mm}$ using a Tritec 2000 dynamic mechanical analyser (Triton Technology, UK). Experiments were conducted at room temperature and five points were measured within each decade. For each indi- vidual scaffold, the data are averaged over three consecutive runs. Five samples were measured for each type of scaffolds. The real (storage modulus), $E^{\prime}$, and the imaginary component (loss modulus), $E^{\prime \prime}$, of the complex modulus, $E^{*}=E^{\prime}+i E^{\prime \prime}$ (with $i=(-1)^{1 / 2}$ ), were recorded against frequency. Reference values for comparison of the compression modulus were collected at a frequency of $1 \mathrm{~Hz}$.

\subsection{Static and dynamic bioactivity studies in a double- chamber bioreactor}

To study the in vitro bioactive behaviour (in vitro bonebonding ability [21]), two different simulated solutions were used. A simulated body fluid (SBF) with ion concentrations $\left(\mathrm{Na}^{+} 142.0, \mathrm{~K}^{+}\right.$5.0, $\mathrm{Mg}^{2+} 1.5, \mathrm{Ca}^{2+}$ 2.5, $\mathrm{Cl}^{-}$103.0, $\mathrm{HCO}_{3}{ }^{2-} 10.0, \mathrm{HPO}_{4}{ }^{2-} 1.0$ and $\left.\mathrm{SO}_{4}{ }^{2-} 0.5 \mathrm{~mm}\right)[21,22] \mathrm{sim}-$ ilar to those of human blood plasma was prepared as described elsewhere [21,22]. A simulated synovial fluid (SSF) was also used to approximate the chemical environment in a human joint. SSF, with ion concentrations of $\mathrm{Na}^{+} 153.1, \mathrm{~K}^{+} 4.2, \mathrm{Cl}^{-} 139.6$ and phosphate buffer $9.6 \mathrm{~mm}$ [23], was prepared by dissolving $0.3 \mathrm{wt} . \%$ hyaluronic acid in PBS to obtain a $\mathrm{pH}$ of 7.4. Hyaluronic acid is a mucopolysaccharide composed of several thousand amino-sugar residues, and is the primary diffuse macromolecule that exists in human synovial fluid [23]. For the static bioactivity tests, polymeric, composite and bilayered scaffold samples $(n=3)$ were suspended and immersed in $50 \mathrm{ml}$ of SBF and SSF separately at $37^{\circ} \mathrm{C}$ and $\mathrm{pH} 7.4$ (physiological conditions) for $0,1,3$ and 14 days. After soaking, the samples were immediately washed with distilled water and dried at room temperature. For the dynamic bioactivity tests, a double-chamber bioreactor was specially designed and set-up according to Fig. 1. For these assays, bilayered scaffolds $(n=2)$ were assembled in the bioreactor using a silicon septum. The SBF and SSF were continuously circulated in physiological conditions ( $\mathrm{pH} 7.4$ and $37^{\circ} \mathrm{C}$ ) using a peristaltic pump for up to 14 days with an available volume of $50 \mathrm{ml}$ of each solution. Scaffold and solution sampling was performed at $0,3,7$ and 14 days.

The scaffold's surface morphology, as well as the presence of elemental $\mathrm{Ca}$ and $\mathrm{P}$ on the scaffold's surface, was analysed both before and after soaking in SBF and SSF, for the different experimental conditions at the different immersion periods. This was done using scanning electron microscopy (SEM) equipment (S360, Leica Cambridge Ltd.) and energy-dispersive spectroscopy (EDS) equipment (Link EXL II, Oxford) coupled to the SEM. Sample surfaces were carbon coated for EDS (Fisons Instruments, Evaporation PSU CA508, UK) or gold sputtered for SEM (Fisons Instruments, Sputter Coater SC502, UK). Microphotographs and spectra were registered for further analysis. Furthermore, the sample solutions were analysed by ICP-OES in order to quantify the elemental concentrations of $\mathrm{Ca}, \mathrm{P}, \mathrm{Si}, \mathrm{Mg}$ and $\mathrm{Na}$ as function of the immersion period. 


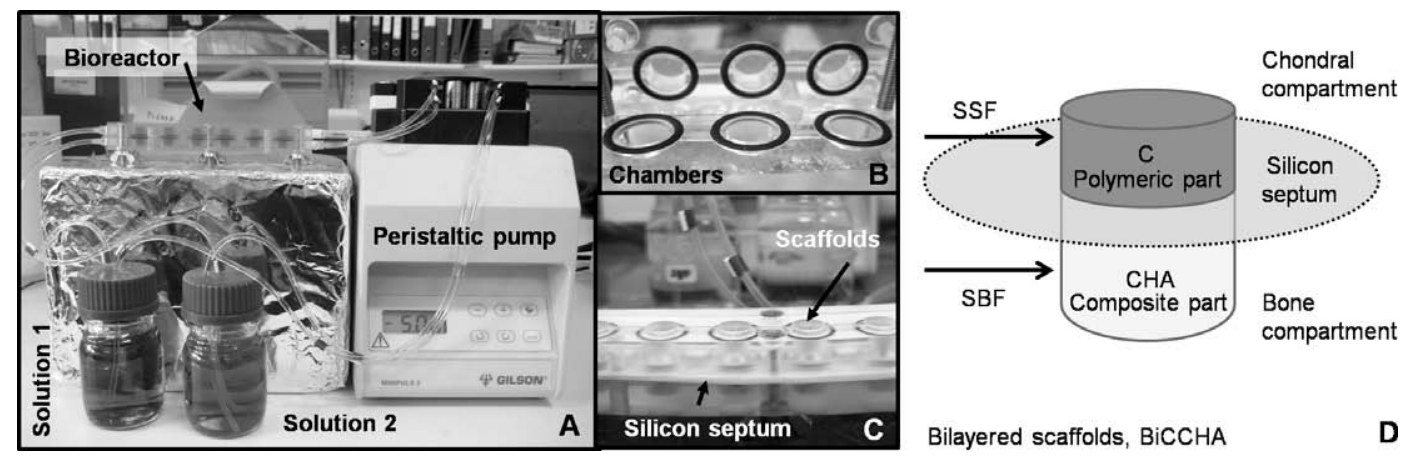

Fig. 1. Double-chamber bioreactor set-up (A). The double-chamber bioreactor consists in six interconnected double-chambers (B) where the different solutions circulate in separate flow circuits. A silicon septum acts as the scaffold's support (C and D). The schematically experimental conditions for the dynamic bioactivity assays are represented in (D).

\subsection{Statistical analysis}

When applicable, statistical analysis of values obtained with the characterization techniques was carried out using Student's two-tailed $t$-test with a confidence level of $99.5 \%$. All statistical calculations were performed with Analysis ToolPak software. Values of $p$ below 0.05 were considered statistically significant.

\section{Results and discussion}

For osteochondral tissue engineering scaffolding, we believe that a bilayered structure is the best approach, as discussed in the introduction. For that, chitosan was chosen as a natural, biodegradable polymeric matrix since it is know that this polymer has a structural similarity to the glycosaminoglycans (GAGs) found in natural extracellular matrices, such as articular cartilage, where it plays a key role in modulating the morphology, differentiation and function of chondrocytes $[17,18]$. For the composite component for the osteogenic part, HA was selected as a filler since this is the main mineral present in the composite structure of natural bone. In this way, it is expected that both chitosan as the chondrogenic component and the presence of HA for the osteogenic part will provide adequate biochemical cues. Although the degradation of the developed scaffolds is not within the scope of the present paper, it should be mentioned that it has previously been shown that chitosan particles degrade in vivo in a period of 6 months [24], since chitosan is a natural biodegradable polymer. It is true that crosslinking can increase the period of degradation, but to demonstrate this influence in the particular case of the developed chitosan particles, it would be necessary to carry out in vivo studies.

\subsection{Cytotoxicity assessment}

Indirect contact tests, such as cytotoxicity tests with MTS, are widely used as a preliminary screening for biomaterials. These biological tests enable one to ensure that the leachables from the materials will not induce any in vitro cytotoxic effect on the cells. MTS tests were performed in order to screen the eventual cytotoxicity of the developed polymeric and composite scaffolds by means of assessing the cell viability of L929 cells cultured with extracts for $72 \mathrm{~h}$. All the cell viability percentages plotted in the following graphs are values relative to the control (100\% considered for L929 cells cultured with cell culture medium). It was verified that extracts from the polymeric chitosan scaffolds (C) did not affect the cellular viability, since similar cellular viability was obtained as in the controls, as shown in Fig. 2. However, and quite surprisingly, it was found that composite scaffolds produced with unsintered HA and crosslinked with glutaraldehyde reduced the cell viability significantly even at low glutaraldehyde concentrations (Fig. 2A). Lower glutaraldehyde concentrations were used since it was previously reported that residual glutaraldehyde may induce a decrease in cell viability due to free aldehyde groups [25]. Nevertheless, crosslinking is desirable to improve the mechanical performance. To try to overcome this problem, composite scaffolds with unsintered HA crosslinked with $0.01 \%$ of glutaraldehyde were treated with different glycine concentrations in order to block any residual free aldehyde groups that could potentially induce this cytotoxic behaviour. The cell viability increased after treatment with the higher concentration of glycine $(1 \mathrm{M})$ independently of the treatment time, even though it was found to be low (around $40 \%$ ), as shown in Fig. 2B.

From these results, one can conclude that the cytotoxicity effect of the composite scaffolds was not being provoked by the glutaraldehyde. Therefore, the unsintered HA was replaced by sintered HA, which is more chemically stable. The effect of both HAs was studied with no crosslinking as a function of concentration. It was found that sintered HA showed a significant increase in cell viability even for such high concentrations as $20 \%$, with no statistical difference from the control and polymeric scaffolds for this concentration. These MTS results are plotted in Fig. 3A. The influence of glutaraldehyde concentration on composite scaffolds with sintered HA was also investigated. No significant decrease in cell viability was observed for the majority 
A

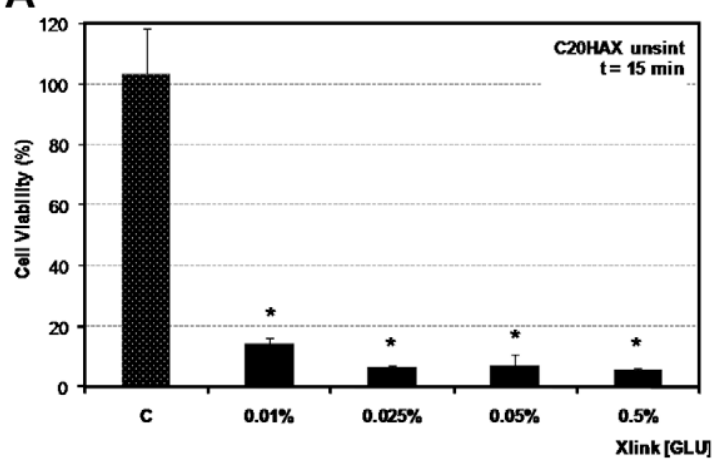

B

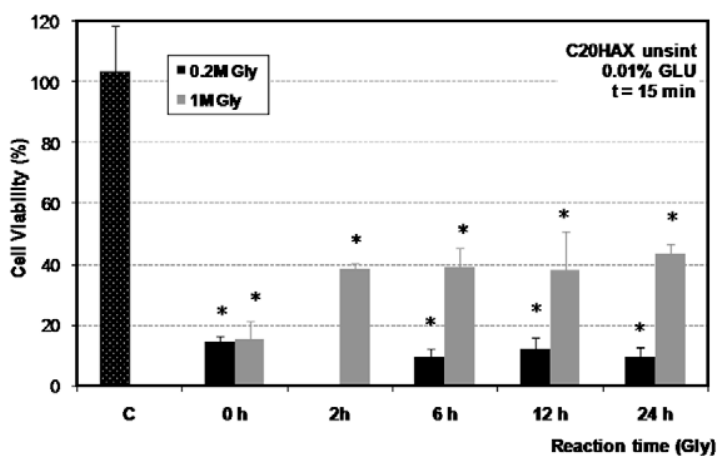

Fig. 2. Cell viability evaluated by MTS assays of composite chitosan particle-aggregated scaffolds showing the influence of glutaraldehyde concentration (A) and glycine treatment (B) when using unsintered HA. C stands for the polymeric scaffolds. *Statistically significantly different to controls and polymeric scaffolds $(\mathrm{C})$.

A

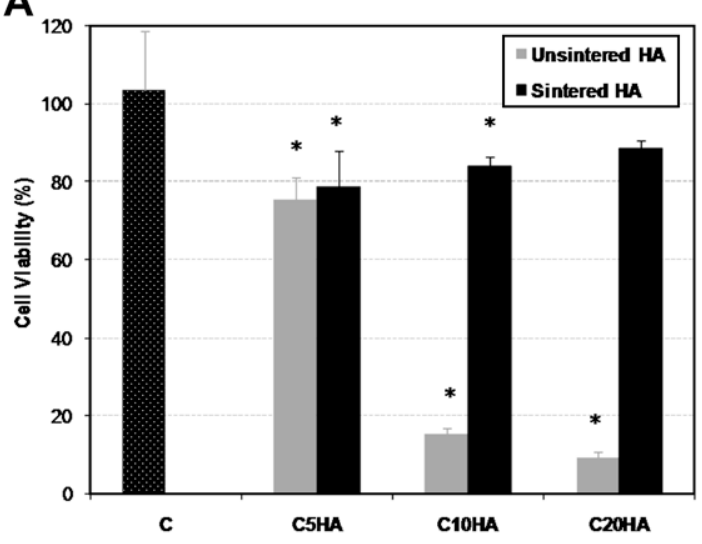

B

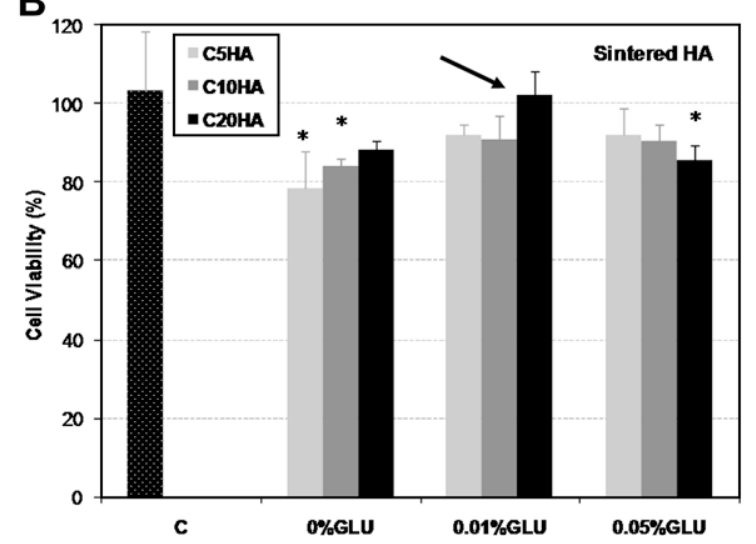

Fig. 3. Influence of unsintered and sintered HA (A) and glutaraldehyde concentrations with $1 \mathrm{M}$ glycine treatment when using sintered HA (B) on cell viability evaluated by MTS assays of composite chitosan particle-aggregated scaffolds. *Statistically significantly different to controls and polymeric scaffolds $(\mathrm{C})$.

of the conditions when compared to the controls and the polymeric scaffolds, as shown in Fig. 3B. In general, when using sintered HA, the obtained values for cell viability for all formulations were completely acceptable for the proposed applications. From these results, composite scaffolds with $20 \mathrm{wt} . \%$ of sintered HA crosslinked with $0.01 \%$ glutaraldehyde and treated with $1 \mathrm{M}$ glycine both for $15 \mathrm{~min}$ were selected and used for further characterization studies, since they have shown higher cell viability with no statistical difference from that of the controls and polymeric scaffolds.

In order to try to understand the cytotoxic behaviour induced by composite scaffolds with unsintered HA, ICP was used to study the extracts from the materials after immersion for $24 \mathrm{~h}$ in cell culture medium following the MTS protocol and using the culture medium as control. ICP results obtained for elemental $\mathrm{Ca}, \mathrm{Mg}, \mathrm{Si}$ and $\mathrm{P}$ concentrations are shown in Fig. 4. Interestingly, it was found that when using composite scaffolds with unsintered HA, the elemental $\mathrm{Ca}$ and $\mathrm{Mg}$ concentrations were statistically lower than in composite scaffolds with sintered HA. When both HAs are incorporated in a chitosan matrix, these ions are taken up by the materials, indicating the formation of an apatite-like layer, as discussed later. It is known that apatites formed in a solution often replace the $\mathrm{Ca}^{2+}$ ion site with small amounts of $\mathrm{Mg}^{2+}, \mathrm{Na}^{+}$or $\mathrm{K}^{+}$ions [26]. Thus, from both ICP and MTS results one can say that this uptake of $\mathrm{Ca}^{2+}$ and $\mathrm{Mg}^{2+}$ ions reached critically low values for the composite scaffolds with unsintered HA, inducing cytotoxic behaviour in these materials. It is known that divalent cations, including $\mathrm{Ca}^{2+}$ and $\mathrm{Mg}^{2+}$, are active in cell adhesion mechanisms, as further discussed elsewhere [27-29].

Fibroblasts, like many other cell types, such as osteoblasts, chondrocytes and endothelial cells, are anchoragedependent cells [30], meaning that they need to adhere to a substrate in order to maintain their function and viability. Furthermore, it is known that cell-cell, cell-extracellular matrix and cell-substrate interactions are mediated by integrins, which are cell adhesion receptors [31]. The extracellular domains of these receptors possess binding sites for a diverse range of protein ligands. Ligand binding is divalent cation dependent and involves well-defined motifs in the ligand [32]. Integrins can dynamically regulate their 


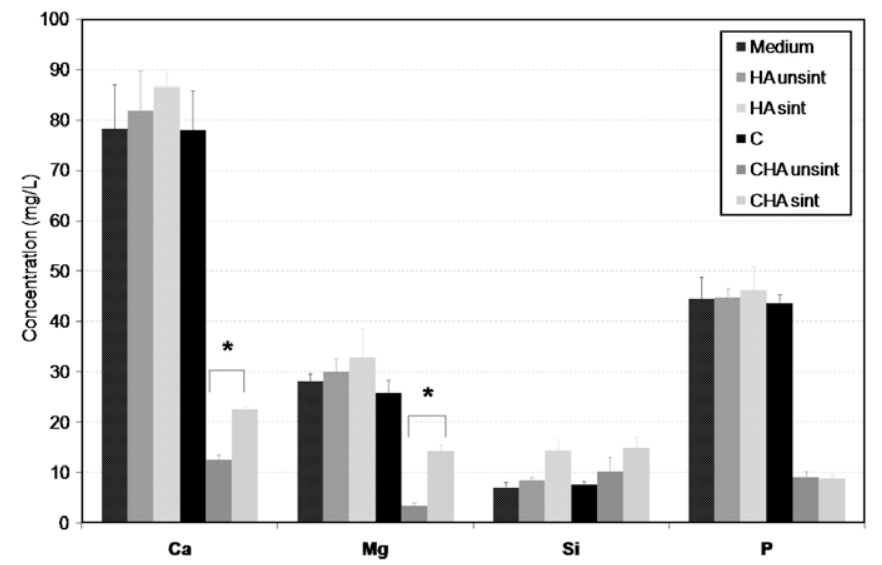

Fig. 4. Elemental $\mathrm{Ca}, \mathrm{Mg}, \mathrm{Si}$ and $\mathrm{P}$ concentrations of materials extracts after a $24 \mathrm{~h}$ immersion in cell culture medium. *Statistically significant difference between conditions. HA unsint. and HA sint. stand, respectively, for unsintered and sintered hydroxyapatite; $\mathrm{C}$ stands for chitosan polymeric scaffolds; and CHA stands for chitosan/hydroxyapatite composite scaffolds. Medium is the control DMEM culture medium.

affinity for ligands; this is a key issue to their involvement in processes such as cell adhesion or cell migration [32]. The cation composition of the extracellular milieu is a potential regulatory factor as the binding of divalent cations to extracellular domains has been shown to activate integrins [28], thereby activating the intracellular signalling pathways. This divalent cation dependence for integrin activation might explain why composite scaffolds produced with unsintered HA showed cytotoxic behaviour. The uptake of divalent cations led to critically low values to be present in the material extracts, thereby compromising cell adherence to the substrate.

In addition to integrins, cells express another $\mathrm{Ca}^{2+}$ -dependent molecule responsible for cell-cell adhesion. The $\mathrm{Ca}^{2+}$-dependent group consists largely of a class of transmembrane glycoproteins called cadherins. These mediate cell-cell adhesion by homotypic protein-protein interactions through their extracellular domain by forming $\mathrm{Ca}^{2+}$ binding sites, which regulate cell adhesion [33]. In the presence of $\mathrm{Ca}^{2+}$, E-cadherin (one subclass of cadherins) resides principally in areas of cell-cell contact. In reduced $\mathrm{Ca}^{2+}$, however, E-cadherin becomes susceptible to proteolytic cleavage and rapidly loses function [34].

Several studies $[27,29,35]$ have reported such divalent cation-dependent behaviour. Paul et al. [29] investigated the behaviour of MG63 osteoblast-like cells when cultured in porous ceramic matrices from nanoparticles of calcium phosphate containing zinc and magnesium. The study showed that the presence of calcium and magnesium in ceramic scaffolds encourages the cell adhesion and spreading of osteoblasts cells onto the bioceramic matrices. In another study, by Fugii et al. [27], the sensitivity to serine proteinases of cellular proteins involved in cell-matrix adhesion was investigated using C 32 melanoma cells. The treatment of cells with serine proteinases can effect integrin-mediated attachment to matrix proteins in a manner moderated by $\mathrm{Ca}^{2+}$. The study showed that in the absence of $\mathrm{Ca}^{2+}$ reduced cell attachment was observed and that the presence of this divalent cation had an additional effect [27]. Furthermore, the divalent cation dependence of fibroblastic cell adhesion to a non-cellular substrate was also demonstrated by Ueda et al. [35]. They showed that $\mathrm{Ca}^{2+}, \mathrm{Mg}^{2+}, \mathrm{Mn}^{2+}$ and $\mathrm{Co}^{2+}$ were effective in promoting the aggregation of fibroblastic cells, as well as their adhesion to the non-cellular substrate.

In conclusion, one may say that the adhesion proteins and their receptors together constitute a versatile recognition system, providing cells with anchorage, traction for migration and signals for polarity, position, differentiation and possibly growth [31]. Since these integrins require divalent cations for ligand binding, one may justify the cytotoxic behaviour of composite scaffolds produced with unsintered HA based in the uptake of these divalent ions to a critically low value. The low concentration of $\mathrm{Ca}^{2+}$ and $\mathrm{Mg}^{2+}$ may compromise the activation of integrins, thereby affecting the adhesion of fibroblasts and, therefore, the cell viability when cultured with the material extracts. However, as mentioned previously, this problem was overcome by using sintered HA, which showed a cell viability similar to that of the control and to the polymeric scaffolds.

\subsection{Morphometric analysis}

When aiming at osteochondral applications, the graft should structurally and functionally integrate with the host tissue, since any discontinuity is likely to cause long-term device failure. To create constructs having more favourable integration properties that might be used as osteochondral tissue engineering scaffolds, we have successfully designed and produced bilayered structures combining polymeric and composite chitosan-based particles by promoting their aggregation.

In order to assess the morphometric characterization of the developed scaffolds, micro-CT was carried out. The 3-D micro-CT technique provides a better understanding of the scaffold's basic properties, thereby allowing for the optimization of their design and the better fulfilment of tissue engineering scaffolding needs. It is thus a valuable instrument to support new fabrication technologies. It provides accurate quantitative 3-D information at the micro-level and in a non-destructive fashion. This justifies its popularity in characterizing porous scaffolds. Relevant morphometric parameters, such as porosity, interconnectivity, pore and particle size, as well as the ceramic and pore size distribution, can be retrieved from this analysis.

The scaffold's porosity and interconnectivity were quantified and are shown in Fig. 5A. The mean total porosity values of $27.78 \pm 2.80 \%, 22.41 \pm 2.79 \%$ and $31.49 \pm$ $3.04 \%$ were obtained with an interconnectivity degree of about $94.97 \pm 1.40 \%, 91.77 \pm 1.91 \%$ and $94.05 \pm 2.43 \%$ for the proposed polymeric, composite and bilayered 
scaffolds, respectively. It is important to stress that the interconnectivity was calculated with a limit in the pore size of $53 \mu \mathrm{m}$ as the minimum value for interconnected pores, meaning that interconnection diameters below this value were considered as closed pores.

One interesting feature of the particle aggregation methodology is that it does not compromise the scaffold's interconnectivity, even at the interface (Fig. 5A). Since this methodology is based on the random assembly of particles, the bonding sites are the contact points of adjacent particles, thereby creating a highly interconnected network. As a result, this strategy does not create any interface barrier area, allowing further cell migration and nutrient flow and thus potentially avoiding necrotic central regions. Moreover, the values of porosity (Fig. 5A) that might be considered low for tissue engineering applications $[7,36]$ are responsible for the high mechanical performance of the materials, which is a critical issue when aiming at load-bearing tissue engineering applications.

Pore size is another important morphological factor for tissue ingrowth, and the scaffolds we developed have a wide
3-D pore size distribution in the range of the optimal pore size, as indicated by different authors [37-39]. These results are demonstrated in Fig. 6, which represents the number of pores in each given size range for the different scaffolds formulations. The mean values of pore diameter and particle size (pore wall thickness) were found to vary between 225 and $290 \mu \mathrm{m}$ and 410 and $460 \mu \mathrm{m}$, respectively, as shown in Fig. 5B.

The different polymeric and ceramic phases present in the samples are characterized by different values of the linear Xray attenuation coefficient. To obtain quantitative data for each analysed scaffold, a histogram was generated plotting the frequency of a given number of voxels as a function of the X-ray absorption coefficient, as presented in Fig. 7A. In the X-ray absorption histograms of the polymeric and composite scaffolds, only one peak was observed for each formulation, corresponding to the chitosan polymeric phase and the chitosan-HA phase, respectively. The mean of the peak related to the composite phase shifted to higher values of linear attenuation coefficient due to the presence of HA. In the case of the bilayered structure samples, both
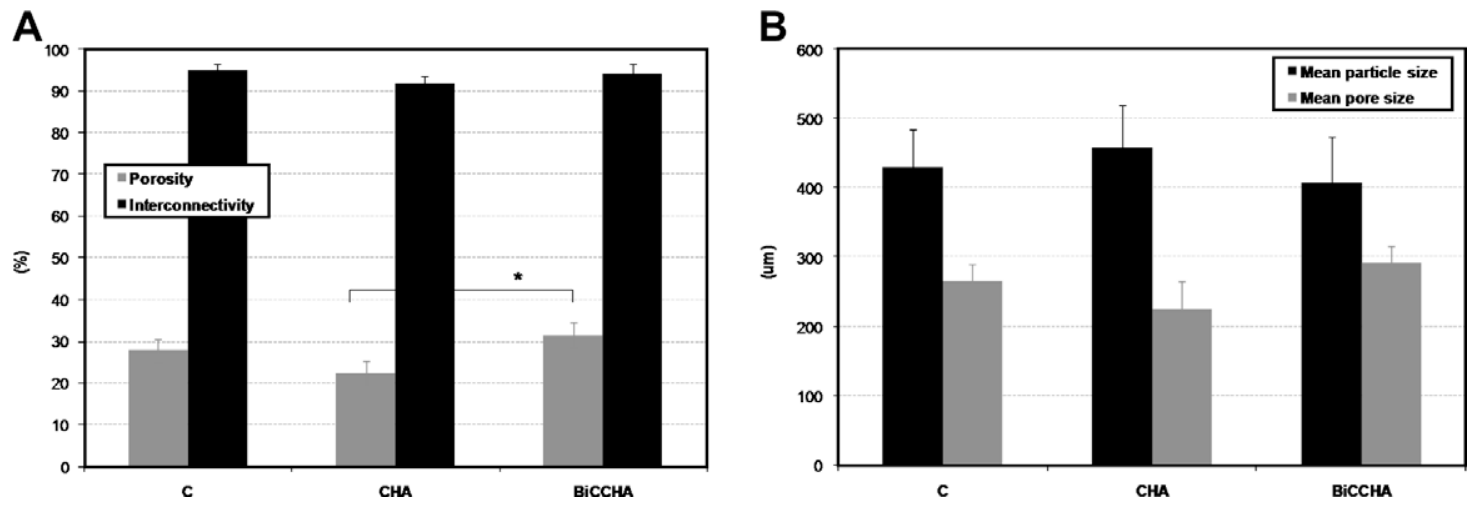

Fig. 5. Porosity and interconnectivity (A) and mean particle and pore size (B) of polymeric, composite and bilayered chitosan particle-aggregated scaffolds measured by micro-CT. * Statistically significant difference between the two formulations. C, CHA and BiCCHA are as for Fig. 4.

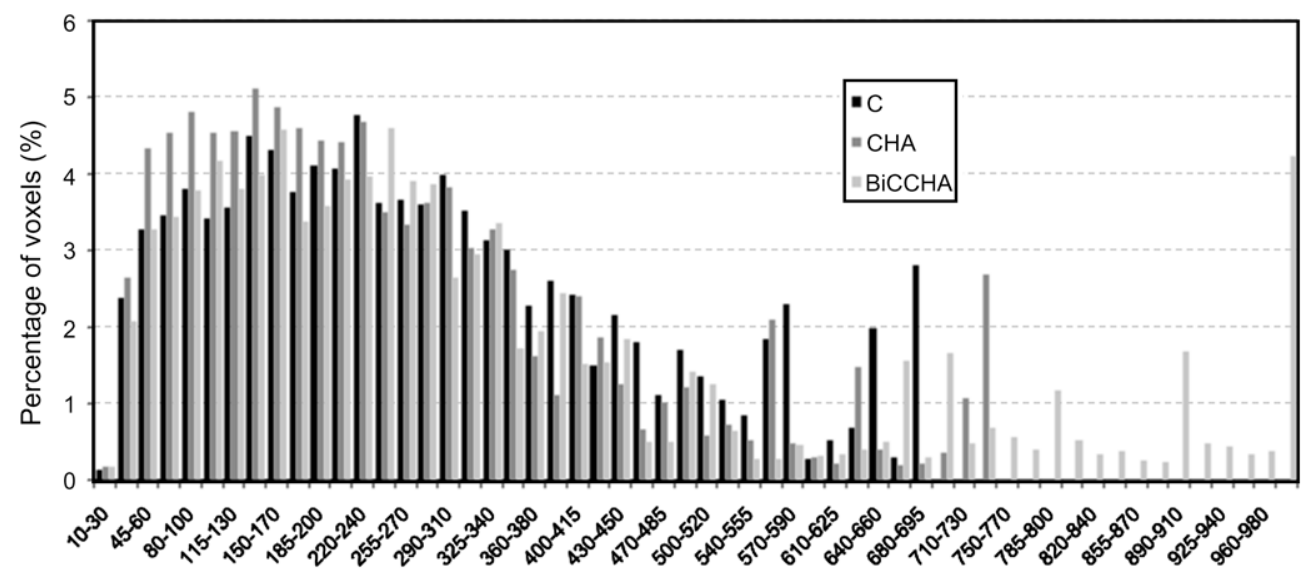

Pore size $(\mu \mathrm{m})$

Fig. 6. Distribution of pore size of polymeric, composite and bilayered chitosan particle-aggregated scaffolds measured by micro-CT. C, CHA and BiCCHA are as for Fig. 4. 
peaks were observed at lower and higher X-ray absorption values, as expected, matching the polymeric and composite phases that comprise this biphasic structure.

The ceramic phase content profile in the scaffolds was also assessed and plotted against the scaffold thickness. These results allow the evaluation of the ceramic distribution along the scaffold, including in the interface of the bilayered structures (Fig. 7B). The steady increase in the ceramic phase in the interface is clear evidence of the gradual transition from the polymeric phase to the composite structure.

The 3-D virtual models presented in Fig. 8 allow the scaffolds' interfaces to be visualized using different thresholds to disclose the spatial distribution of both the polymeric and the ceramic matrix in the central part of the scaffolds. From these images, we can see that good integration of both phases is achieved with this processing methodology using chitosan as the polymeric matrix without the need for any extra joining technique. This is due to the bioadhesive properties of chitosan [40]. One can conclude that a successful approach was achieved by means of assembling polymeric and composite chitosan-based particles in order to fabricate an integrated two-phase scaffold for osteochondral tissue engineering.

\subsection{Dynamical-mechanical behaviour}

As discussed previously, large osteochondral defects are associated with mechanical instability [5]. Therefore, the mechanical properties of the scaffold or engineered tissue before implantation into an osteochondral defect are key determinants of its long-term success or eventual failure. Furthermore, the mechanical properties of a scaffold will influence the mechanical environment of the seeded cells [41].

When designing a complex osteochondral construct, it is desirable that the heterogeneous structures be built in such a way that one of the sides promotes cartilage regeneration and the other side, exhibiting different properties, supports bone integration. For example, the cartilage-side layer should be more ductile and should have a much greater fluid uptake capability [9]. However, it is predicted that increasing the stiffness of the scaffold to a certain level increases the amount of cartilage formation and reduces the amount of fibrous tissue formation in the defect [41]. The bone-side layer should exhibit greater stiffness, should preferably have a good affinity to the ceramic constituent of bone and, ideally, should be able to induce vascularization, especially for large defects [9].

In the present study, bilayered structures were designed with these considerations in mind. For the chondrogenic part, chitosan polymeric particles were assembled while for the osteogenic constituent composite particles were used with HA as a ceramic filler and were further crosslinked with glutaraldehyde in order to improve the component's stiffness. The assessment of the scaffold's mechanical behaviour is essential to demonstrate its mechanical stability, namely in dynamic conditions and in a hydrated state resembling the conditions in vivo, where physiological fluids are present. For that purpose, chitosan-based scaffolds were fully hydrated in PBS for 3 days in physiological conditions, based on previous hydration studies which showed that after this time period a hydration plateau was achieved (data not shown). Chitosan-based particle-aggregated scaffolds in this wet state were then characterized under dynamic compression over a range of physiological frequencies in load-bearing applications, such as articular cartilage or bone $[14,42]$. The values at a frequency of $1 \mathrm{~Hz}$ were considered as reference values for comparisons of the elastic (storage) and viscous (loss) components of the complex modulus, and are shown in Fig. 9A.

From these results, we can first conclude that the scaffolds showed very good mechanical properties compared to those obtained for chitosan-based porous materials $[43,44]$, even if only considering the polymeric formulation. The mean values for the elastic component $\left(E^{\prime}\right)$ were found to be $4.21 \pm 1.04,7.98 \pm 1.77$ and $6.26 \pm 1.04 \mathrm{MPa}$ for polymeric, composite and bilayered scaffolds, respectively. The high mechanical properties obtained by the particle aggregation methodology are further supported by the findings of another study, namely that of Jiang et al. [45], who used chitosan microspheres with poly(lactic acid-glycolic acid) sintered together to obtain the final 3-D structure. $E^{\prime}$ was further increased for the composite scaffolds
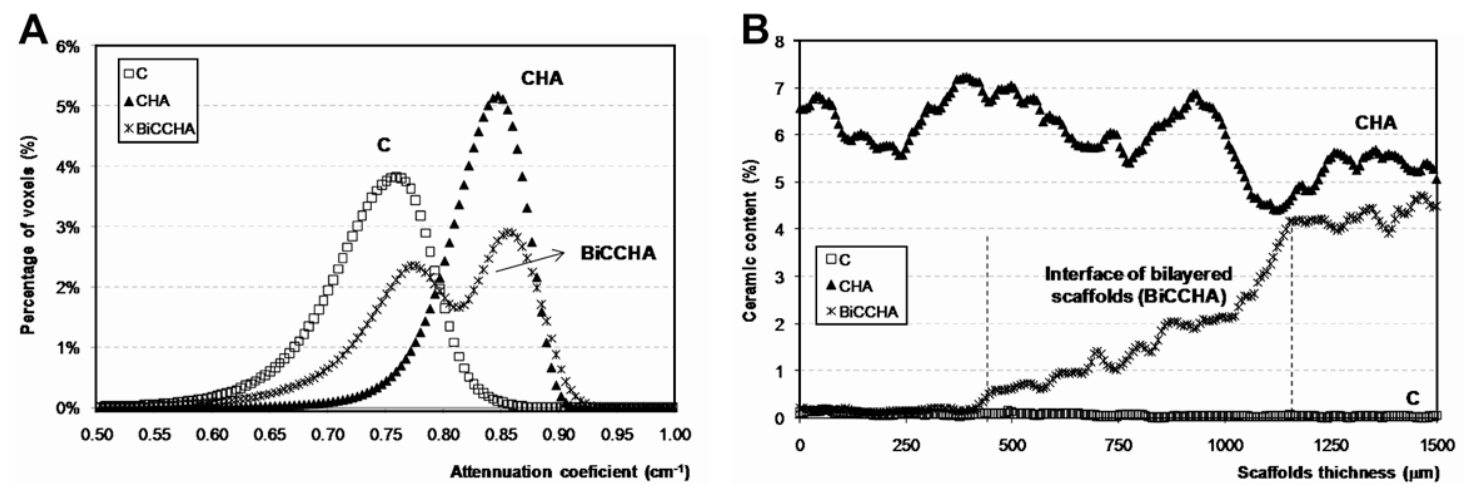

Fig. 7. Representative X-ray absorption histogram (A) and ceramic content distribution (B) obtained for polymeric, composite and bilayered chitosan particle-aggregated scaffolds. C, CHA and BiCCHA are as for Fig. 4. 


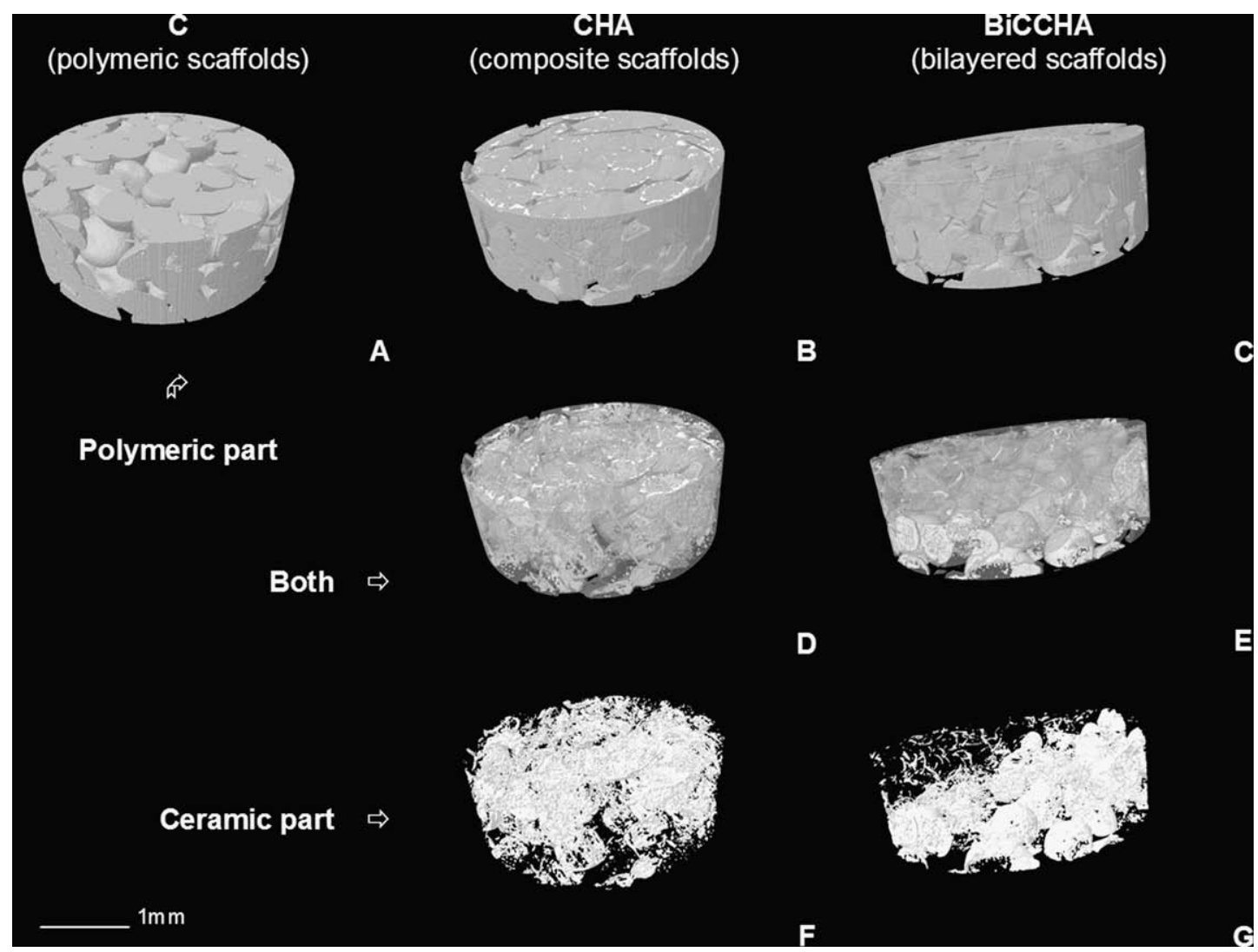

Fig. 8. Three-dimensional virtual models of chitosan particle-aggregated scaffolds: polymeric $(\mathrm{C} ; \mathrm{A})$, composite $(\mathrm{CHA} ; \mathrm{B}, \mathrm{D}$ and F) and bilayered (BiCCHA; C, E and G) scaffolds, showing the gradual transition (D and E) that shows the ceramic phase distribution (F and $\mathrm{G})$.
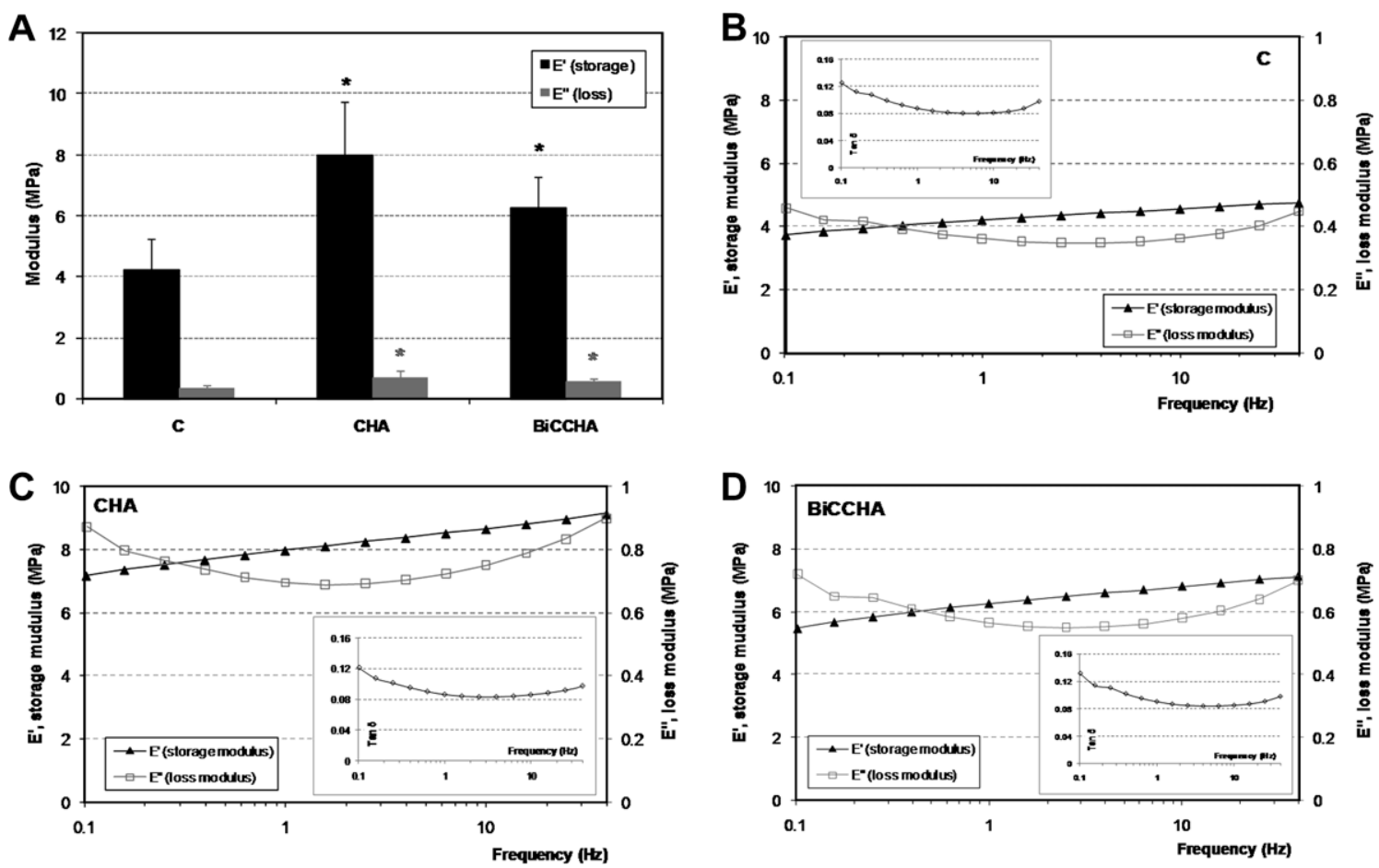

Fig. 9. Storage $\left(E^{\prime}\right)$ and loss $\left(E^{\prime \prime}\right)$ moduli under dynamic compression solicitation at $1 \mathrm{~Hz}$ frequency (A) and behaviour for increasing frequencies (B, C and D) of polymeric (C), composite (CHA) and bilayered (BiCCHA) chitosan particle-aggregated scaffolds in the wet state. The inset graphs show the frequency dependence of the loss factor $(\tan \delta)$. ${ }^{*}$ Statistically significantly different compared to the polymeric scaffolds. 
by incorporating $\mathrm{HA}$ and crosslinking the polymeric matrix to obtain a scaffold with greater stiffness, as envisioned for the osteogenic component. A twofold increase in $E^{\prime}$ was achieved and, as expected, the bilayered materials presented an intermediate value between the polymeric and composite scaffolds since they are both the basis of its structure.

In addition, the storage $\left(E^{\prime}\right)$ and loss $\left(E^{\prime \prime}\right)$ modulus behaviours for increasing frequencies are presented in Fig. 9B-D, with the frequency dependences of the loss factor $(\tan \delta)$ shown in the inset graphs. As can be seen, the developed materials showed the same profiles for storage $\left(E^{\prime}\right)$ and loss $\left(E^{\prime \prime}\right)$ moduli with increasing frequencies. The elastic modulus $\left(E^{\prime}\right)$ increases with increasing frequency, being typically between 4 and $9 \mathrm{MPa}$, while the viscous modulus $\left(E^{\prime \prime}\right)$ shows the inverse trend, increasing for higher frequencies, this behaviour being more obvious for composite materials.

As a consequence, there is a decrease in the loss factor $\left(\tan \delta=E^{\prime \prime} / E^{\prime}\right)$ with increasing frequency, with a slight increase for higher frequencies, as shown in the inset graphs. This factor measures the proportion of the imposed mechanical stress that is dissipated in the form of heat. As $\tan \delta$ is typically above 0.08 for $f<1 \mathrm{~Hz}$, one may conclude that the scaffolds possess significant damping capability, which may be useful in dissipating some of the cyclic mechanical energy that is imposed in an implantation scenario. Nevertheless, there is an increase in $E^{\prime \prime}$ for high frequencies, which suggests that the material exhibits some dissipation capability for high frequencies.

By dynamically testing the bilayered scaffolds in wet conditions in a physiological range of frequencies, we were able to demonstrate that these biphasic materials are mechanically stable even for higher frequencies, showing once again the high level of integration between the two components.

\subsection{Static and dynamic in vitro bioactivity studies}

The in vitro bioactivity studies were performed to address two hypotheses, since we are discussing the potential application in osteochondral tissue engineering. On one hand, one should assure that the polymeric component designed for the chondrogenic part will not mineralize even with the extra supply of $\mathrm{Ca}$ and $\mathrm{P}$ from the composite component. To preliminarily screen this behaviour, SSF was also used in order to mimic the chemical environment of a human joint. On the other hand, we needed to evaluate the ability for the composite component designed for the osteogenic part to form per se an apatite layer on its surface. This can predict the bone-bonding ability of the material, which is often evaluated in SBF [21].

For this, the osteogenic component was designed as a polymer composite, which includes a bioactive ceramic phase (HA) as the source of both bioactivity and reinforcement incorporated into the polymeric matrix. The composite component thus potentially has the capability of combining bioactive behaviour with improved mechanical performance, as discussed previously. This strategy was first used to produce HA-polyethylene bioactive composites [46], and was also applied to develop composites containing other bioactive phases, such as bioactive glasses [47] and glass ceramics [48], and a series of different polymers $[46,47,49]$.

To address both hypotheses, in vitro bioactivity studies were carried out using two different simulated solutions (SBF and SSF) in both static and dynamic conditions. The aim of the dynamic strategy was to approach the ideal scenario required to engineer in vitro an osteochondral construct.

The SEM microphotographs for static conditions are disclosed in Fig. 10, where it is possible to analyse the scaffold's surface before and after 14 days of immersion in both SBF and SSF. In the figure, no significant morphological changes could be seen in the scaffold's surface, even after 14 days of immersion in both simulated solutions. In the case of composite components, this may be due to the presence of HA already in the surface, which makes it very irregular and so could mask any apatite formation.

However, from the ICP results (Fig. 11) there is a clear evidence of the $\mathrm{Ca}$ and $\mathrm{P}$ concentration decrease in the solution from both composite and bilayered scaffolds indicating that these materials are consuming these ions for an apatite formation. As can be seen, a sharp decrease in the Ca concentration of SBF (Fig. 11A) takes place in the first 7 days of immersion for composite and bilayered samples, stabilizing at a certain value up to 14 days. The same trend is observed for the $\mathrm{P}$ concentration (Fig. 11B), which becomes stable after 3 and 7 days for SSF and SBF, respectively.

Interestingly, ICP revealed the selective absorption of $\mathrm{Ca}$ and $\mathrm{P}$ for the bilayered structures, since these materials show a higher amount of both $\mathrm{Ca}$ and $\mathrm{P}$ present in solution when compared to composite samples. This selective absorption was further confirmed by EDS (Fig. 12), with no Ca and P being detected at the surface of the polymeric component after 14 days of immersion in both solutions (Fig. 12B). In addition, an increase in the $\mathrm{Ca}$ and $\mathrm{P}$ peak intensity for the composite constituent can be observed, which becomes even clearer when immersed in SBF (Fig. 12C).

From these results, one can conclude that both hypotheses were addressed, since in static conditions the polymeric component designed for the chondrogenic part did not mineralized in vitro and the composite part consumes both $\mathrm{Ca}$ and $\mathrm{P}$ from the simulated solutions to form an apatite layer.

To study the in vitro bioactivity in dynamic conditions, we designed a specific double-chamber bioreactor (see Fig. 1). The ultimate goal is for this design to be used in future studies to engineer bilayered hybrid constructs for osteochondral applications. For this, the bioreactor was designed to allow the simultaneous culturing of chondrocytes and osteoblasts in the respective sections of a single-unit chamber. 


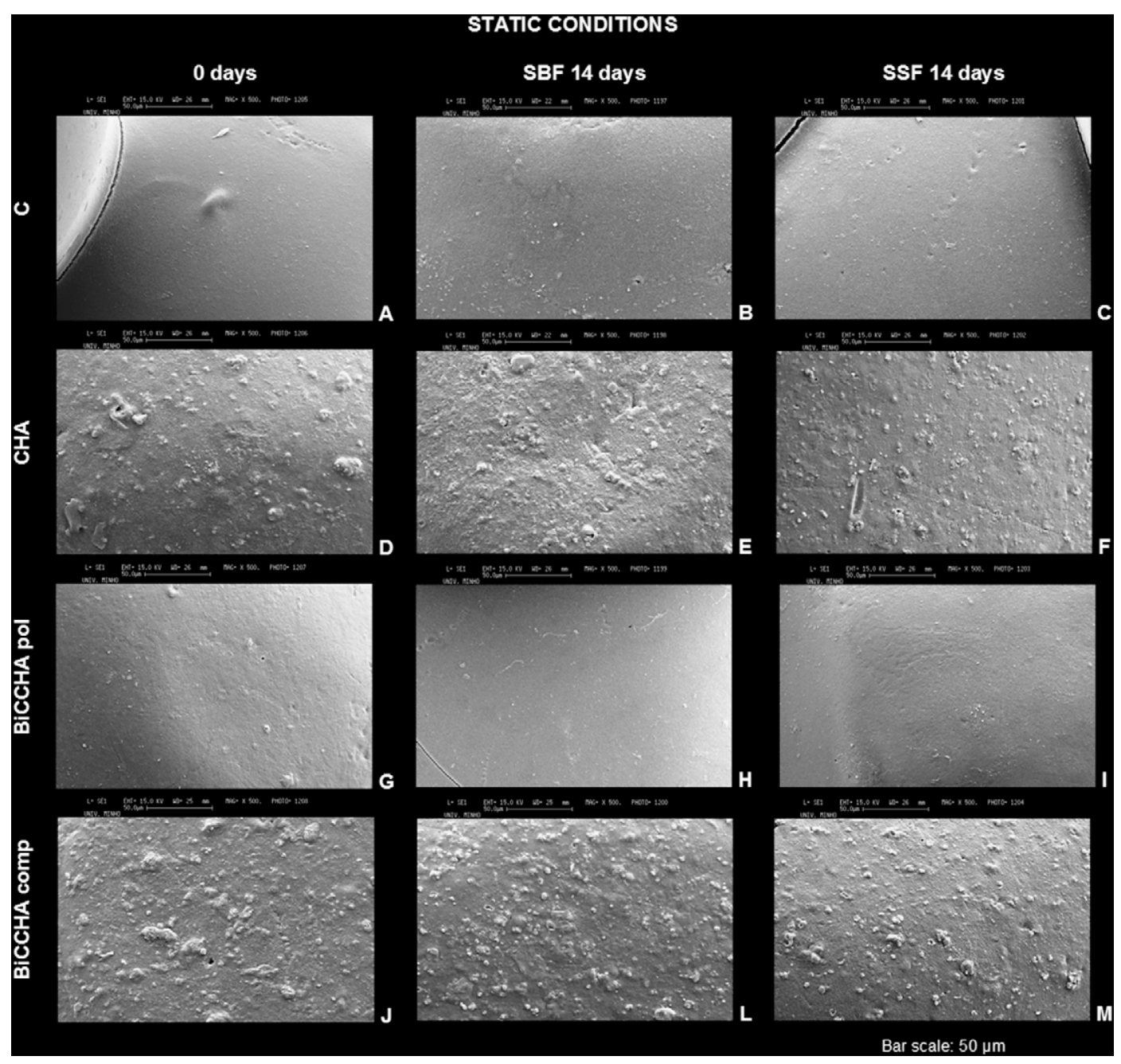

Fig. 10. SEM microphotographs of scaffolds surface before (A, D, G and J) and after 14 days of immersion in SBF (B, E, H and L) and SSF (C, F, I and M) in static conditions. C stands for polymeric scaffolds (A, B and C), CHA for composite scaffolds (D, E and F), BiCCHA pol for the surface of the polymeric part $(\mathrm{G}, \mathrm{H}$ and $\mathrm{I})$ and BiCCHA comp for the surface of the composite part ( $\mathrm{J}, \mathrm{L}$ and $\mathrm{M}$ ) of the bilayered scaffolds. The bar scale represents $50 \mu \mathrm{m}$.
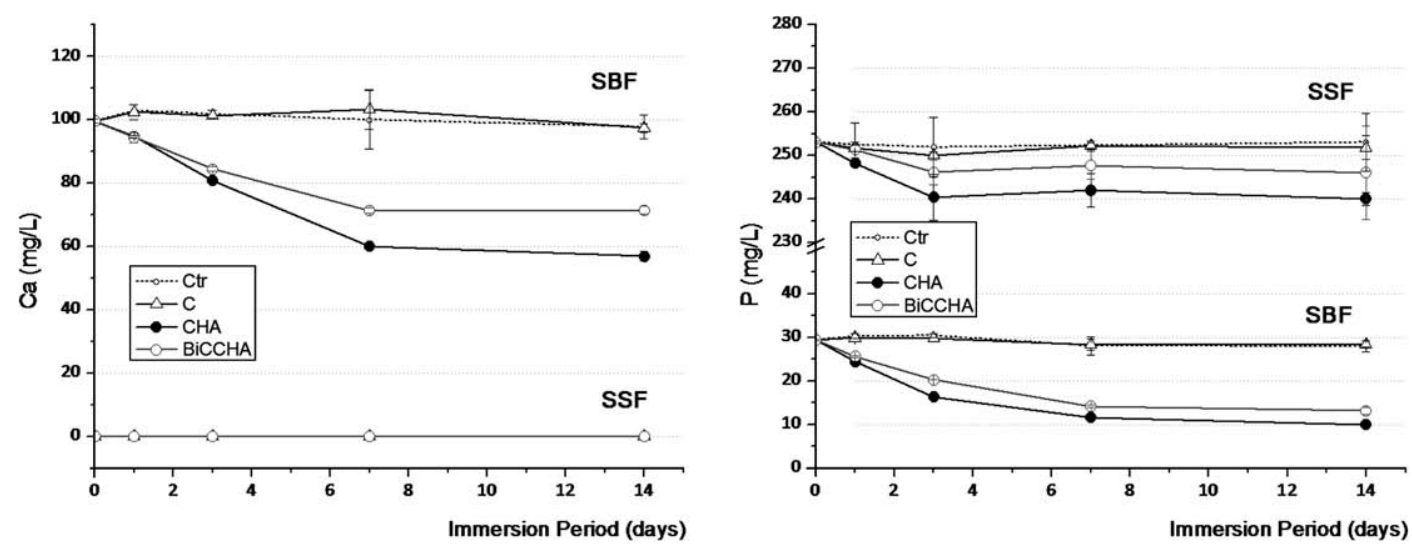

Fig. 11. Calcium (A) and phosphorous (B) concentration profiles of SBF and SSF as a function of immersion time of polymeric (C), composite (CHA) and bilayered (BiCCHA) scaffolds in static conditions.

The scaffolds are supported by a transversal silicon membrane and both simulated solutions (SBF and SSF) are continuously recirculated in the six interconnected chambers in each respective part of the bilayered scaffold. This also promotes dynamic perfusion and a laminar flow in each of the bioreactor compartments, thereby contribut- 


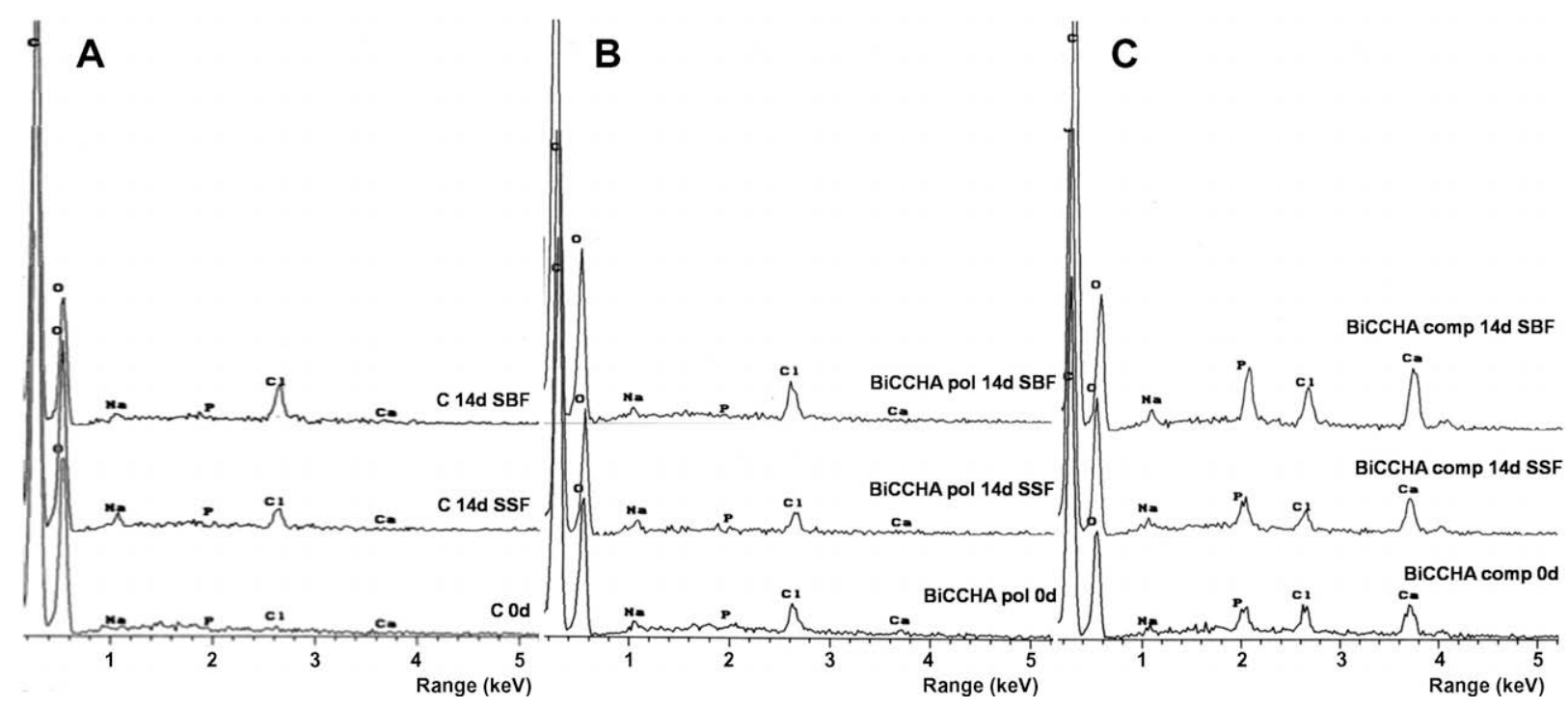

Fig. 12. EDS spectra showing the presence of calcium and phosphorous in the surface of polymeric scaffolds (A), polymeric part of bilayered scaffolds (BiCCHA pol; B) and ceramic part of bilayered scaffolds (BiCCHA comp; C) before and after 14 days of immersion in SBF and SSF in static conditions.

ing to enhanced cell distribution and the mass transfer of nutrients and avoiding the potential necrotization of the central regions. SBF has a flow circuit through the composite parts of the bilayered structures while SSF circulates through the polymeric part designed for the chondral constituent to approximate the chemical environment in a human joint.

Similarly to the static conditions, the SEM microphotographs of the dynamic assays did not show any significant morphological changes in either the polymeric or the composite surfaces of the bilayered scaffolds, as shown in The concentration profiles of $\mathrm{Ca}$ and $\mathrm{P}$ of both simulated solutions (SBF and SSF) in the double-chamber bioreactor assessed by ICP analysis are shown in Fig. 14. Through the first 7 days, the Ca concentration of SBF decreased significantly from 100 to around $40 \mathrm{mg}^{-1}$ (Fig. 14A). The Ca concentration then seems to stabilize. An inverse profile is observed for the Ca concentration of SSF, with a clear increase within the first 3 days that becomes less attenuated over longer periods. Exactly the same trend profile is observed for the P concentration (Fig. 14B), only in this case the SSF solution supplies $\mathrm{P}$ to the SBF. This is an indication of the ion exchange between both simulated solutions in the double-chamber bioreactor.

We calculated and compared the consumption of $\mathrm{Ca}$ and $\mathrm{P}$ of the bilayered structures by subtracting the constant initial value from the total concentration at a given time period (dashed grey line in Fig. 13). It can be seen that the consumption of $\mathrm{Ca}$ gradually increases up to 7 days, before stabilizing. The same trend is observed for the $\mathrm{P}$ concentration, with a tendency to increase slightly after 3 days of immersion. This consumption data clearly indicate that the $\mathrm{Ca}$ and $\mathrm{P}$ are being captured by the materials, which is one of the criteria for the evaluation of the in vitro bioactivity of materials.
These results were further complemented by EDS analysis (Fig. 15), which showed that neither $\mathrm{Ca}$ nor $\mathrm{P}$ was detected at the surface of the polymeric component after 14 days in the double-chamber bioreactor and showed an increase in the $\mathrm{Ca}$ and $\mathrm{P}$ intensity peaks for the composite part even after only 3 days. This is clear evidence that these ions are being selectively consumed by the composite part of the bilayered structures.

The studies with the double-chamber bioreactor show its potential since the scaffolds were able to withstand the perfusion rates. With the proposed design, the medium flow direction can be inverted at certain interval periods, in order to promote increased homogeneity and charge distribution. Ion exchange between the two simulated solutions was observed due to the high interconnectivity of the developed scaffolds that allowed the solutions to exchange with time. This can be considered as a disadvantage when aiming to engineer an osteochondral hybrid construct using the same source of progenitor cells with different differentiation cell culture media, or the simultaneous but independent culturing of chondrocytes and osteoblasts.

Nevertheless, we have to consider that in cell culture assays the culture media are frequently mixed to supply the adequate concentration of nutrients. Furthermore, if desirable, the materials can be designed with a physical barrier between the chondrogenic and osteogenic components without compromising the integration of the scaffolds. In the case of chitosan-based materials, a chitosan membrane can be assembled when producing the materials since this polymer is known to be bioadhesive [40]. Furthermore, as one of the ongoing strategies with chitosan-based particle-aggregated scaffolds, the physical barrier can be accomplished using a hydrogel for the chondrogenic component where chondrocytes can be encapsulated. 


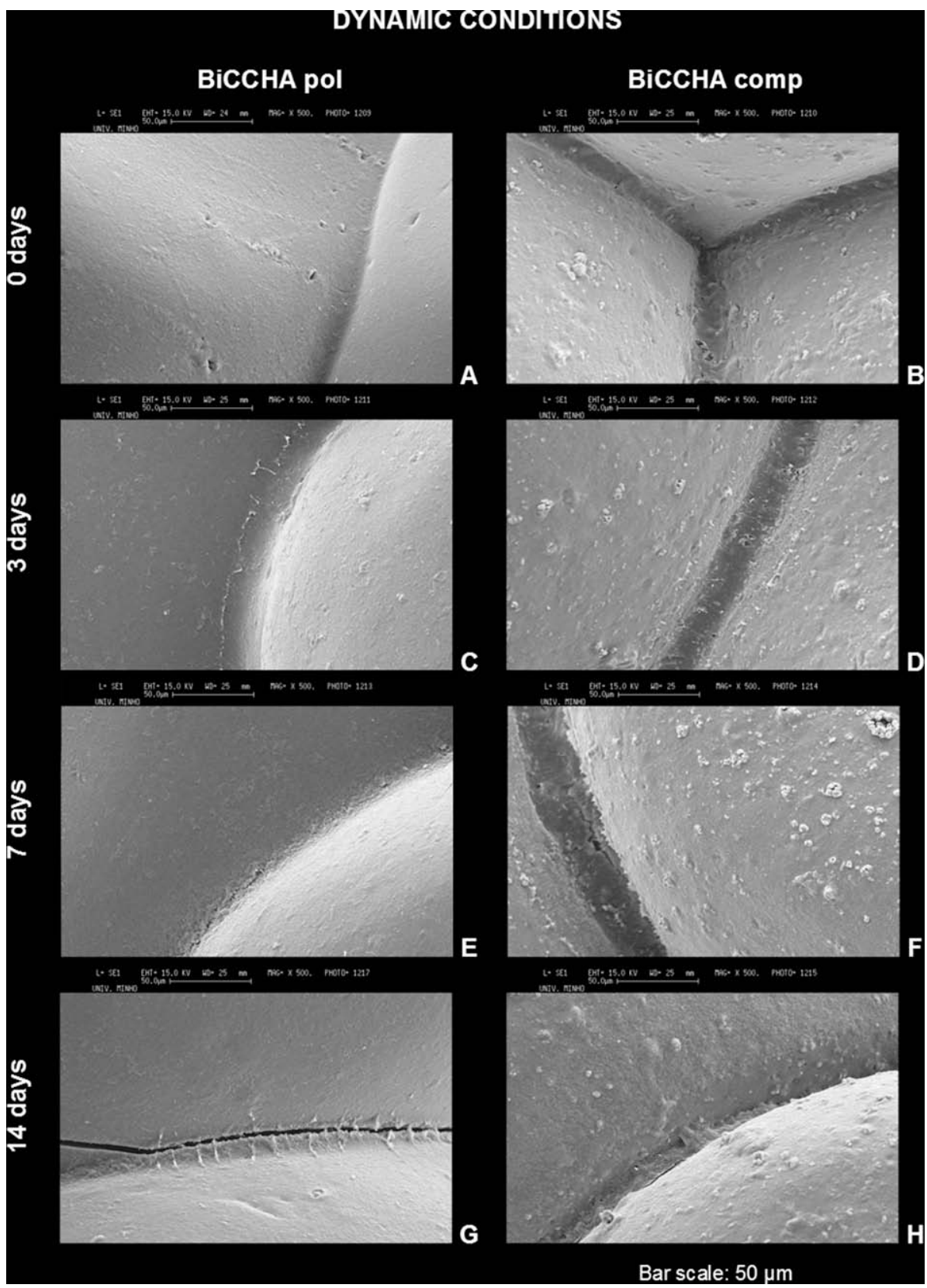

Fig. 13. SEM microphotographs of scaffolds surface before (A and B) and after 3 (C and D), 7 (E and F) and 14 days $(G$ and $H)$ of dynamic bioactivity assay in the double-chamber bioreactor where SBF and SSF were circulating. BiCCHA pol stands for the surface of the polymeric part (A, C, E and G) while BiCCHA comp stands for the surface of the composite part (B, D, F and H) of the bilayered scaffolds. The bar scale represents $50 \mu \mathrm{m}$.

Alternatively, some authors $[8,50,51]$ defend the application of a single-phase material, but with gradients of molecular, structural and functional properties, to engineer complex tissue grafts, as discussed in the introduction. As an example, Vunjak-Novakovic et al. [8] proposed a single-phase silk-based scaffold which is functionalized by covalently binding growth factors with spatial concentration gradients, with opposing gradients of a chondrogenic factor (IGF-I) and an osteogenic factor (BMP-2) for tissue engineering of osteochondral grafts. The opposite gradients of these two different growth factors in the same scaffold are proposed in order to mimic the "ideal" concentration of IGF-I for cartilage at one end and the "ideal" concentration of BMP-2 for bone at the other end [8].

It is possible for the double-chamber bioreactor, or the materials to be used within it, to be further optimized in future studies for engineer osteochondral hybrid constructs. Nevertheless, in the present study, a double-chamber bioreactor was successfully designed to study the in vitro bioactivity behaviour in dynamic conditions.

\section{Conclusions}

By using a simple particle aggregation method, it was possible to obtain bilayered chitosan-based scaffolds that 

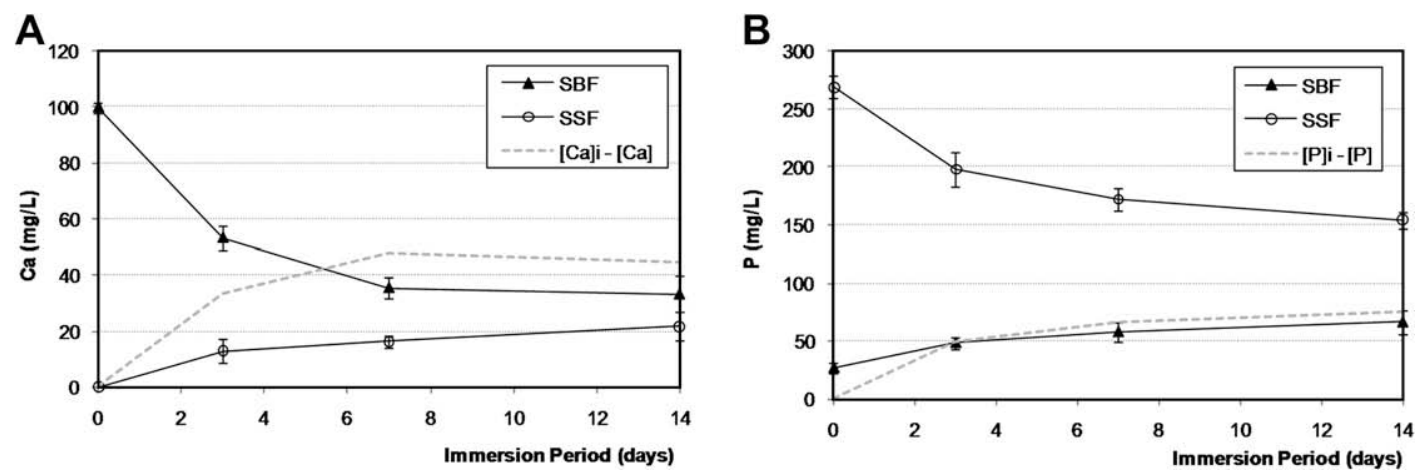

Fig. 14. Calcium (A) and phosphorous (B) concentration profiles of SBF and SSF as a function of time in the double-chamber bioreactor with the bilayered chitosan-based scaffolds. $[\mathrm{Ca}]_{\mathrm{i}}-[\mathrm{Ca}]$ and $[\mathrm{P}]_{\mathrm{i}}-[\mathrm{P}]$ represent the initial total concentration of each element minus the concentration of each element at a given time period.

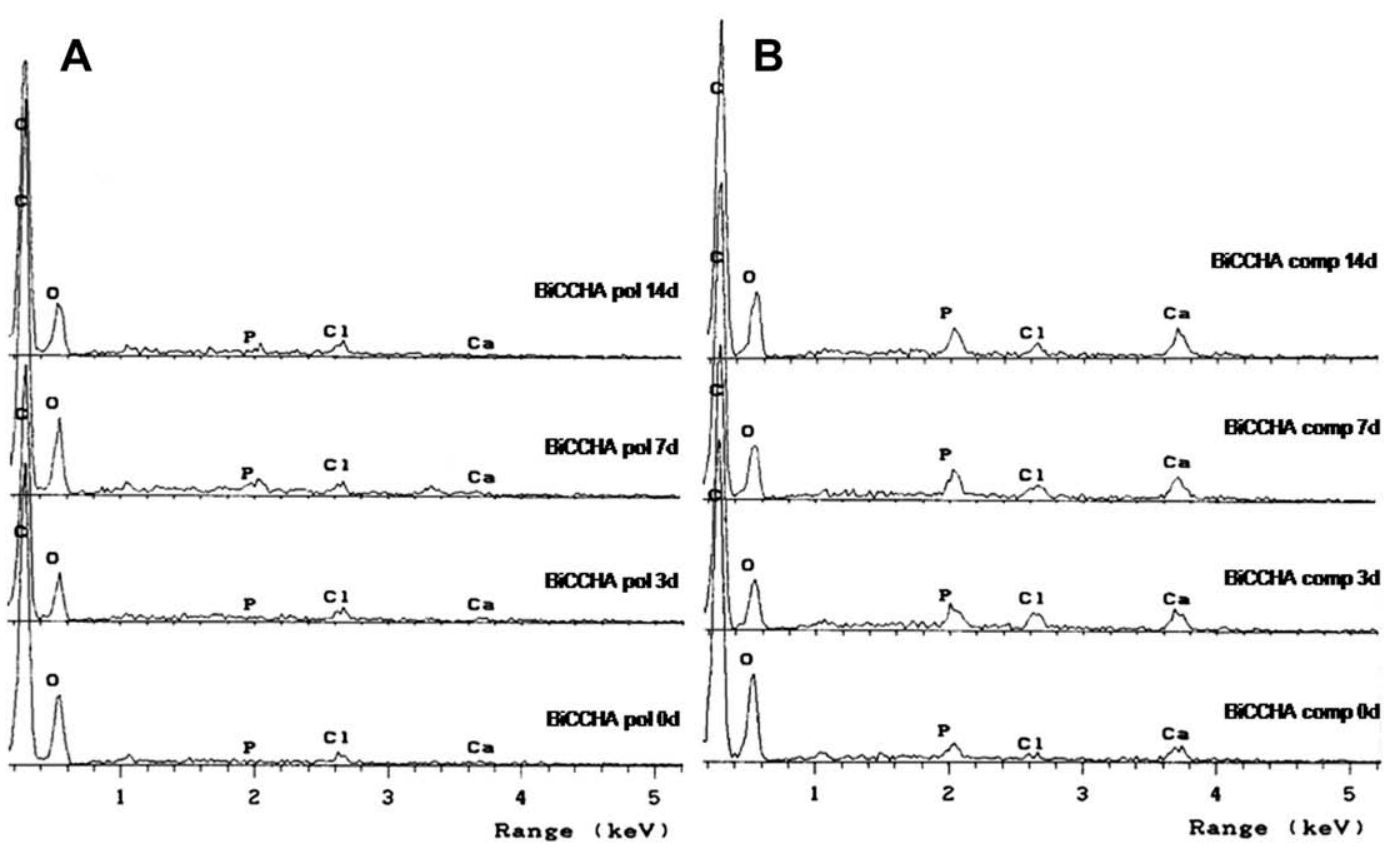

Fig. 15. EDS spectra showing the presence of calcium and phosphorous in the surface of polymeric part of bilayered scaffolds (BiCCHA pol; A) and ceramic part of bilayered scaffolds (BiCCHA comp; B) for 0, 3, 7 and 14 days in the double-chamber bioreactor.

exhibit very promising properties for osteochondral applications. The risk of possible delamination between both polymeric and composite components designed for chondrogenic and osteogenic constituents, respectively, was avoided since the materials showed an integrated interface assessed by micro-CT, as well as mechanical stability in the wet state under dynamic compression. It is suggested that the unexpected cytotoxic behaviour of composite materials produced with unsintered HA could be explained by the critically low concentrations of $\mathrm{Ca}$ and $\mathrm{Mg}$ found in the extracts. This low divalent cation concentration might affect the activation of integrins, compromising the cell adhesion and, therefore, the cell viability. This unexpected result was overcome by means of using sintered HA, which showed no cytotoxic behaviour. From the overall results of the in vitro bioactivity assays, both addressed hypotheses were corroborated, since in static conditions the polymeric component designed for the chondrogenic part did not mineralized in vitro and the composite part selectively consumes both $\mathrm{Ca}$ and $\mathrm{P}$ from the simulated solutions to form an apatite layer. Furthermore, a specific double-chamber bioreactor was successfully designed for in vitro bioactivity tests in dynamic conditions, also aimed at use in future studies to engineer osteochondral hybrid constructs.

\section{Acknowledgements}

The authors acknowledge the Portuguese Foundation for Science and Technology for the Ph.D. grant to P.B. Malafaya (SFRH/BD/11155/2002). This work was partially supported and carried out under the scope of the European STREP Project HIPPOCRATES 
(NMP3-CT-2003-505758) and European NoE EXPERTISSUES (NMP3-CT-2004-500283). The authors would thank Adriano Pedro, for preliminary help with the MTS assays and bioreactor design, and João T. Oliveira, for assistance with the DMA equipment, both from the 3B's Research Group; and Lina Carvalho and Eugénio Soares, from Central Laboratory of Analysis, University of Aveiro, for their promptness with the ICP analysis.

\section{References}

[1] Marcacci M, Kon E, Delcogliano M, Filardo G, Busacca M, Zaffagnini S. Arthroscopic autologous osteochondral grafting for cartilage defects of the knee: prospective study results at a minimum 7-year follow-up. Am J Sports Med 2007;35(12):2014-21.

[2] Lee CY, Liu X, Hsu HC, Wang DY, Luo ZP. A modified cell culture method for autologous chondrocyte transplantation. Connect Tissue Res 2005;46(2):93-9.

[3] Ait Si Selmi T, Neyret P, Verdonk PCM, Barnouin L. Autologous chondrocyte transplantation in combination with an alginate-agarose based hydrogel (Cartipatch). Tech Knee Surg 2007;6(4):253-8.

[4] Swieszkowski W, Tuan BHS, Kurzydlowski KJ, Hutmacher DW. Repair and regeneration of osteochondral defects in the articular joints. Biomol Eng 2007;24(5):489-95.

[5] Schaefer D, Martin I, Jundt G, Seidel J, Heberer M, Grodzinsky A, et al. Tissue-engineered composites for the repair of large osteochondral defects. Arthritis Rheum 2002;46(9):2524-34.

[6] Schaefer D, Martin I, Shastri P, Padera RF, Langer R, Freed LE, et al. In vitro generation of osteochondral composites. Biomaterials 2000;21(24):2599-606.

[7] Hollister SJ. Porous scaffold design for tissue engineering. Nat Mater 2005;4(7):518-24.

[8] Vunjak-Novakovic G, Meinel L, Altman G, Kaplan D. Bioreactor cultivation of osteochondral grafts. Orthod Craniofac Res 2005;8(3):209-18.

[9] Mano JF, Reis RL. Osteochondral defects: present situation and tissue engineering approaches. J Tissue Eng Regen Med 2007;1(4):261-73.

[10] Martin I, Miot S, Barbero A, Jakob M, Wendt D. Osteochondral tissue engineering. J Biomech 2007;40(4):750-65.

[11] Huang X, Yang D, Yan W, Shi Z, Feng J, Gao Y, et al. Osteochondral repair using the combination of fibroblast growth factor and amorphous calcium phosphate/poly(L-lactic acid) hybrid materials. Biomaterials 2007;28(20):3091-100.

[12] Wendt D, Jakob M, Martin I. Bioreactor-based engineering of osteochondral grafts: from model systems to tissue manufacturing. J Biosci Bioeng 2005;100(5):489-94.

[13] Chang CH, Lin CC, Chou CH, Lin FH, Liu HC. Novel bioreactors for osteochondral tissue engineering. Biomed Eng - Appl Basis Commun 2005;17(1):38-43.

[14] Munirah S, Samsudin OC, Chen HC, Sharifah Salmah SH, Aminuddin BS, Ruszymah BHI. Articular cartilage restoration in loadbearing osteochondral defects by implantation of autologous chondrocyte-fibrin constructs: an experimental study in sheep. J Bone Joint Surg - Ser B 2007;89(8):1099-109.

[15] Robertson WB, Fick D, Wood DJ, Linklater JM, Zheng MH, Ackland TR. MRI and clinical evaluation of collagen-covered autologous chondrocyte implantation $(\mathrm{CACI})$ at two years. Knee 2007;14(2):117-27.

[16] Scotti C, Buragas MS, Mangiavini L, Sosio C, Di Giancamillo A, Domeneghini $\mathrm{C}$, et al. A tissue engineered osteochondral plug: an in vitro morphological evaluation. Knee Surg Sports Traumatol Arthrosc 2007;15(11):1363-9.

[17] Malafaya PB, Silva GA, Reis RL. Natural-origin polymers as carriers and scaffolds for biomolecules and cell delivery in tissue engineering applications. Adv Drug Deliv Rev 2007;59(4-5):207-33.
[18] Mano JF, Silva GA, Azevedo HS, Malafaya PB, Sousa RA, Silva SS, et al. Natural origin biodegradable systems in tissue engineering and regenerative medicine: present status and some moving trends. J R Soc Interface 2007;4(17):999-1030.

[19] Malafaya PB, Pedro A, Peterbauer A, Gabriel C, Redl H, Reis RL. Chitosan particles agglomerated scaffolds for cartilage and osteochondral tissue engineering approaches with adipose tissue derived stem cells. J Mater Sci Mater Med 2005;16(12):1077.

[20] Reis RL, Mendes SC, Cunha AM, Bevis MJ. Processing and in-vitro degradation of starch/EVOH thermoplastic blends. Polym Int 1997;43:347-53.

[21] Kokubo T, Takadama H. How useful is SBF in predicting in vivo bone bioactivity? Biomaterials 2006;27(15):2907-15.

[22] Oyane A, Kim H-M, Furuya T, Kokubo T, Miyazaki T, Nakamura T. Preparation and assessment of revised simulated body fluids. J Biomed Mater Res Part A 2003;65A(2):188-95.

[23] Conzone SD, Brown RF, Day DE, Ehrhardt GJ. In vitro and in vivo dissolution behavior of a dysprosium lithium borate glass designed for the radiation synovectomy treatment of rheumatoid arthritis. J Biomed Mater Res 2002;60(2):260-8.

[24] Durkut S, Elçin YM, Elçin AE. Biodegradation of chitosan-tripolyphosphate beads: in vitro and in vivo studies. Artif Cells Blood Substit Biotechnol 2006;34(2):263-76.

[25] Zhang YZ, Venugopal J, Huang ZM, Lim CT, Ramakrishna S. Crosslinking of the electrospun gelatin nanofibers. Polymer 2006;47(8):2911-7.

[26] Oliveira AL, Malafaya PB, Reis RL. Sodium silicate gel as a precursor for the in vitro nucleation and growth of a bone-like apatite coating in compact and porous polymeric structures. Biomaterials 2003;24(15):2575-84.

[27] Fujii K, Lazarus GS, Schechter NM. Modification of integrinmediated cell attachment to substrata by serine proteinases in the presence and absence of divalent cations. Exp Cell Res 1993;208(1):94-103.

[28] Hughes PE, Pfaff M. Integrin affinity modulation. Trends Cell Biol 1998;8(9):359-64.

[29] Paul W, Sharma CP. Effect of calcium, zinc and magnesium on the attachment and spreading of osteoblast like cells onto ceramic matrices. J Mater Sci Mater Med 2007;18(5):699-703.

[30] Lopez-Perez PM, Marques AP, Silva RMPD, Pashkuleva I, Reis RL. Effect of chitosan membrane surface modification via plasma induced polymerization on the adhesion of osteoblast-like cells. J Mater Chem 2007;17(38):4064-71.

[31] Ruoslahti E, Pierschbacher M. New perspectives in cell adhesion: RGD and integrins. Science 1987;238(4826):491-7.

[32] Tozer EC, Hughes PE, Loftus JC. Ligand binding and affinity modulation of integrins. Biochem Cell Biol 1996;74(6):785-98.

[33] Tuan RS. Molecular basis of cell-cell interaction and signalling in mesenchymal chondrogenesis. In: Massaro EJ, Rogers JM, editors. The skeleton: biochemical, genetic, and molecular interactions in development and homeostasis. Totowa, NJ: Humana Press; 2004. p. 3-15.

[34] Grzesiak JJ, Pierschbacher MD. Shifts in the concentrations of magnesium and calcium in early porcine and rat wound fluids activate the cell migratory response. J Clin Invest 1995;95(1): 227-33.

[35] Ueda MJ, Takeichi M. Two mechanisms in cell adhesion revealed by effects of divalent cations. Cell Struct funct 1976;1(4):377-88.

[36] Hutmacher DW. Scaffolds in tissue engineering bone and cartilage. Biomaterials 2000;21(24):2529-43.

[37] Otsuki B, Takemoto M, Fujibayashi S, Neo M, Kokubo T, Nakamura T. Pore throat size and connectivity determine bone and tissue ingrowth into porous implants: three-dimensional micro-CT based structural analyses of porous bioactive titanium implants. Biomaterials 2006;27(35):5892-900.

[38] Bobyn JD, Pilliar RM, Cameron HU, Weatherly GC. The optimum pore size for the fixation of porous surfaced metal implants by the ingrowth of bone. Clin Orthop Relat Res 1980;150:263-70. 
[39] Whang K, Elenz DR, Nam EK, Tsai DC, Thomas CH, Nuber GW, et al. Engineering bone regeneration with bioabsorbable scaffolds with novel microarchitecture. Tissue Eng 1999;5(1):35-51.

[40] Kim IY, Seo SJ, Moon HS, Yoo MK, Park IY, Kim BC, et al. Chitosan and its derivatives for tissue engineering applications. Biotechnol Adv 2008;26(1):1-21.

[41] Kelly DJ, Prendergast PJ. Prediction of the optimal mechanical properties for a scaffold used in osteochondral defect repair. Tissue Eng 2006;12(9):2509-19.

[42] Garner E, Lakes R, Lee T, Swan C, Brand R. Viscoelastic dissipation in compact bone: implications for stress-induced fluid flow in bone. $\mathrm{J}$ Biomech Eng 2000;122(2):166-72.

[43] Huang Y, Onyeri S, Siewe M, Moshfeghian A, Madihally SV. In vitro characterization of chitosan-gelatin scaffolds for tissue engineering. Biomaterials 2005;26(36):7616-27.

[44] Wan Y, Fang Y, Wu H, Cao X. Porous polylactide/chitosan scaffolds for tissue engineering. J Biomed Mater Res - Part A 2007;80A(4):776-89.

[45] Jiang T, Abdel-Fattah WI, Laurencin CT. In vitro evaluation of chitosan/poly(lactic acid-glycolic acid) sintered microsphere scaffolds for bone tissue engineering. Biomaterials 2006;27(28):4894-903.
[46] Bonfield W, Grynpas MD, Tully AE. Hydroxyapatite reinforced polyethylene - a mechanically compatible implant material for bone replacement. Biomaterials 1981;2(3):185-6.

[47] Leonor IB, Sousa RA, Cunha AM, Reis RL, Zhong ZP, Greenspan D. Novel starch thermoplastic/Bioglass ${ }^{\circledR}$ composites: mechanical properties, degradation behavior and in-vitro bioactivity. J Mater Sci Mater Med 2002;13(10):939-45.

[48] Juhasz JA, Best SM, Brooks R, Kawashita M, Miyata N, Kokubo T, et al. Mechanical properties of glass-ceramic A-W-polyethylene composites: effect of filler content and particle size. Biomaterials 2004;25(6):949-55.

[49] Borden M, Attawia M, Khan Y, Laurencin CT. Tissue engineered microsphere-based matrices for bone repair: design and evaluation. Biomaterials 2002;23(2):551-9.

[50] Guo X, Wang C, Duan C, Descamps M, Zhao Q, Dong L, et al Repair of osteochondral defects with autologous chondrocytes seeded onto bioceramic scaffold in sheep. Tissue Eng 2004;10:1830-40.

[51] Solchaga LA, Temenoff JS, Gao J, Mikos AG, Caplan AL, Goldberg VM. Repair of osteochondral defects with hyaluronan- and polyesterbased scaffolds. Osteoarthritis Cartilage 2005;13:297-309. 